\title{
Differential expression analysis of Trichoderma virens RNA reveals a dynamic transcriptome during colonization of Zea mays roots
}

\author{
Elizabeth A. Malinich, Ken Wang, Prasun K. Mukherjee, Michael Kolomiets and Charles M. Kenerley*
}

\begin{abstract}
Background: Trichoderma spp. are majorly composed of plant-beneficial symbionts widely used in agriculture as bio-control agents. Studying the mechanisms behind Trichoderma-derived plant benefits has yielded tangible bioindustrial products. To better take advantage of this fungal-plant symbiosis it is necessary to obtain detailed knowledge of which genes Trichoderma utilizes during interaction with its plant host. In this study, we explored the transcriptional activity undergone by $T$. virens during two phases of symbiosis with maize; recognition of roots and after ingress into the root cortex.

Results: We present a model of T. virens - maize interaction wherein T. virens experiences global repression of transcription upon recognition of maize roots and then induces expression of a broad spectrum of genes during colonization of maize roots. The genes expressed indicate that, during colonization of maize roots, T. virens modulates biosynthesis of phytohormone-like compounds, secretes a plant-environment specific array of cell wall degrading enzymes and secondary metabolites, remodels both actin-based and cell membrane structures, and shifts metabolic activity. We also highlight transcription factors and signal transduction genes important in future research seeking to unravel the molecular mechanisms of $T$. virens activity in maize roots.

Conclusions: $T$. virens displays distinctly different transcriptional profiles between recognizing the presence of maize roots and active colonization of these roots. A though understanding of these processes will allow development of $T$. virens as a bio-control agent. Further, the publication of these datasets will target future research endeavors specifically to genes of interest when considering $T$. virens - maize symbiosis.
\end{abstract}

Keywords: Trichoderma virens, Zea mays, Root colonization, Transcriptome, Phytohormone, Cell wall degrading enzymes, Secondary metabolites, RNA-seq, Differential expression

\section{Background}

Trichoderma (teleomorph Hypocrea) is a well-established fungal genus that has been the subject of numerous reviews [1-4]. In brief, Trichoderma spp. are mycoparasitic, facultative plant-symbionts that colonize a broad range of plant root systems. Trichoderma-derived plant benefits include enhanced lateral root development, increased nutrient uptake, resistance to abiotic stressors such as heavy metals and reactive oxygen species, and

\footnotetext{
* Correspondence: c-kenerley@tamu.edu

Department of Plant Pathology and Microbiology, Texas A\&M University, College Station, TX, USA
}

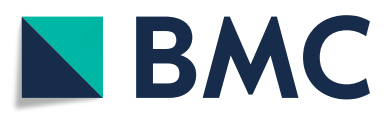

(c) The Author(s). 2019 Open Access This article is distributed under the terms of the Creative Commons Attribution 4.0 International License (http://creativecommons.org/licenses/by/4.0/), which permits unrestricted use, distribution, and reproduction in any medium, provided you give appropriate credit to the original author(s) and the source, provide a link to the Creative Commons license, and indicate if changes were made. The Creative Commons Public Domain Dedication waiver (http://creativecommons.org/publicdomain/zero/1.0/) applies to the data made available in this article, unless otherwise stated. ISR (induced systemic resistance). Consequently, Trichoderma spp. are widely used as agricultural bio-control agents. While new molecular investigative techniques have exponentially advanced our knowledge of Trichoderma, much remains to be discovered on the mechanisms by which Trichoderma spp. affect plants.

It is understood that Trichoderma colonizes plant roots in stages: first, actively growing towards roots indicative of root recognition, then growing externally on the root surface, followed by ingress in to the root cortex $[5,6]$. A recent study by Nogueira-Lopez et al. [7] 
suggested that $T$. virens may colonize intracellularly and locate within the periplasmic space of the plant cell. During $T$. virens attachment to and invasion of plant root cells hydrophobin and cell wall degrading enzymes play an important role [8]. There is no detailed model, however, for the which particular enzymes and extracellular structures are used in root colonization and how they are regulated.

Once inside the plant, Trichoderma spp. effect change on phytohormone levels, specifically of phytohormones jasmonic acid (JA) and salicylic acid (SA) which pay central roles in orchestrating plant defense. It has been shown that $T$. virens generally suppresses SA in early colonization and then enhances JA levels to mediate ISR [9-12]. Plant growth hormones, i.e. indole-3-acetic acid (IAA), also have a correlational response to Trichoderma colonization of plant roots [13]. The molecular mechanisms behind $T$. virens influence on these phytohormones are a subject of current interest.

Many secreted proteins, metabolites, and enzymes also are known to play roles in Trichoderma - plant symbiosis. SM1 is a secreted protein of T. virens which suppresses the maize gene $Z m L O X 3$ to stimulate ISR [1416]. Peptaibols, produced from non-ribosomal protein synthases, can affect both plant growth and disease resistance $[17,18]$. Cell wall degrading enzymes (CWDE) are utilized for colonization - these also have current biotechnology applications. For example, CWDE isolated from $T$. reesei are already used for potent cocktails to degrade biofuel feedstock [19]. Continued exploration of the secondary metabolites, secreted proteins, and enzymes which Trichoderma utilizes within a plant host is important to informing future bio-industrial products. For example, supporting crop growth on marginal land would be benefitted by fostering Trichoderma's ability to mitigate abiotic stress on plants, and optimization of bio-control agents requires a thorough understanding of how influential proteins are regulated and secreted.

In this study we sought to accelerate research targeted at Trichoderma plant interactions by using RNA-sequencing to conduct a comprehensive survey of the transcriptional activity experienced by $T$. virens co-cultivated with maize (Zea mays) during the recognition and after the ingress stages of root colonization. We anticipate that this study will accomplish two purposes. One, it will highlight important processes undertaken by $T$. virens for a productive root-symbiont relationship. Two, it will detail specific enzymes, proteins, metabolites, and other molecules which $T$. virens utilizes in the maize host, thus increasing precision of future studies.

\section{Results and discussion}

\section{Differential expression analysis}

The Trichoderma virens transcriptome was analyzed after 6 and $30 \mathrm{~h}$ of co-cultivation with maize. These timepoints were defined, respectively, as the "Recognition" phase, wherein $T$. virens was visibly growing towards maize but had not yet penetrated the roots, and the "Colonization" phase, wherein T. virens had made ingress into the maize root (see Methods and Additional file 1: Figure S2). Differential expression (DE) analysis was used to analyze each transcriptome. $T$. virens gene expression during Recognition was compared to gene expression of $T$. virens grown for $6 \mathrm{~h}$ alone; likewise, T. virens gene expression during Colonization was compared to $T$. virens growth for $30 \mathrm{~h}$ alone. This was done to minimize the impact of fungal aging and circadian rhythm on the $\mathrm{DE}$ analysis. The terminology 'repressed' is used to describe genes with a negative $\log _{2}$ fold change, i.e. were less abundant when $T$. virens was grown with maize, and 'enhanced' to describe genes with a positive $\log _{2}$ fold change, i.e. were more abundant when $T$. virens was co-cultivated with maize. A full list of genes with $\log _{2}$ fold changes and FPKM (fragments per kilobase of transcript per million reads) values can be found in Additional file 2: Data file S1. A differentially expressed gene (DEG) was considered significant if it had a $\log _{2}$ fold change of \pm 1.5 over the control sample and a false-discovery adjusted $p$-value of $<0.05$ (See Additional file 3: Data file S2 for list of all DEGs so discovered). The RNA-seq based DE analysis was validated with RT-qPCR (Additional file 4: Figure S1). Log $_{2}$ fold change calculated as calculated by RT-qPCR and the DE analysis were consistent in terms of direction (i.e. DEGs repressed in the $\mathrm{DE}$ analysis were also repressed when measured by RT-qPCR). The magnitude of the $\log _{2}$ fold change was not as well conserved. This is explicable by the differences in cDNA preparation and that the tissue used for RT-qPCR had been stored for a year, abet at $-80^{\circ} \mathrm{C}$ (See Methods). Pearson correlation, however, was 0.75 when plotting $\log _{2-}$ fold changes obtained by DE vs RT-qPCR.

\section{Differential expression overview}

T. virens altered expression of $6 \%$ of its genome during the Recognition phase and 12\% during the Colonization phase. The altered transcriptomes during each phase represent different subsets of the $T$. virens genome as there was little commonality between DEGs from the Recognition and Colonization datasets (Fig. 1a). Only 204 DEGs were constitutively repressed or enhanced from Recognition to Colonization. Further, the range of $\log _{2}$ fold change was significantly different between the Recognition and Colonization phases, with the Recognition phase DEGs being generally repressed and Colonization DEGs being generally enhanced (Fig. 1b).

For downstream analysis each DEG was manually sorted into a functional group (See Methods and Additional file 3: Data file S2). A total of 347 and 679 genes for Recognition and Colonization, respectively, could not be placed into any category due to 


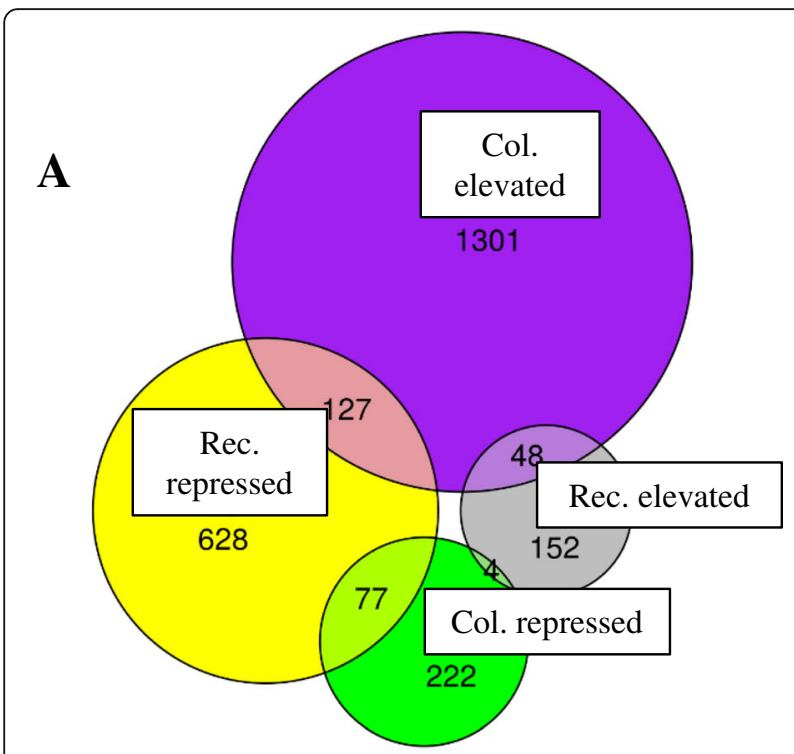

B

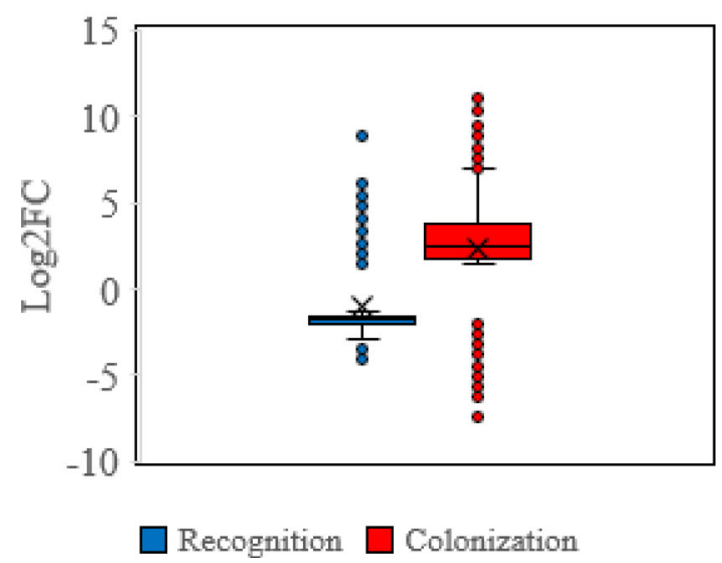

Fig. 1 Recognition and Colonization datasets bear little similarity. a Venn diagram showing the number of DEGs which overlap between the Recognition and Colonization dataset. $\mathbf{b}$ Boxplot of the range of $\log _{2}$ fold changes occurring in each dataset. Students t-test shows a significant difference between the range of $\log _{2}$ fold changes in the datasets, $<0.00001 p$-value

lack of information or poor characterization. Removal of No KOG/poor characterization DEGs left 450 significant DEGs in the Recognition dataset and 875 significant DEGs in the Colonization dataset. Even within individual functional categories, the trend of DEG repression during Recognition and elevation during Colonization was conserved. Below we use the expression of DEGs within each functional category to build a hypothetical framework of $T$. virens activity with maize. For ease of presentation we break down our analysis into four sections: Plant-Related Activity, Environmental Interaction, Fungal Internal Processes, and Fungal Metabolism and Energy.

\section{Plant-related activity}

Plant cell wall degrading enzyme DEGs A total of 28 and 88 DEGs were annotated as being carbohydrate activated enzymes (CAZ) in Recognition and Colonization, respectively. These DEGs ranged across multiple glycosyl hydrolase/transferase families. The importance of glycosyl hydrolases in T. virens colonization of maize and tomato has been noted in previous studies [20, 21]. We focus here on the CAZ specifically annotated as being cell wall degrading enzymes (CWDE), including chitinases, cellulases, pectinases, arabinofuranosidases, laccases and other lignin-degrading enzymes [22]. While these CWDE's may have been involved in mycoparatism or self-cell wall remodeling, the presence of lignin and pectin degrading enzymes suggests catabolism of plant cell walls was likely occurring [22, 23]. Whether this catabolism functioned to aid $T$. virens ingress of root intercellular spaces or served as a nutritional source in planta is unclear [22-24].

In general, the CWDE's were either not significant or repressed during Recognition; coordinating well with the data that the fungus had not yet made ingress into the plant roots. The repression of specific CWDE may also be linked to avoidance of plant defenses. CWDE's have been shown to elicit plant defense as PAMPs in other organisms [25-28]. Five putative CWDE's were, however, still enhanced during Recognition. Two of these were chitinases also enhanced during Colonization (DEGs 150035 and 42107). A further two chitinases (DEGs 63350 and 66683) were repressed in both datasets (Fig. 2).

During T. virens colonization of maize, pectinases appeared to play a highly important role. The highest transcriptional enhancement was a pectin-degrading enzyme (DEG 41602), which expression was $11 \log _{2}$ fold more abundant than the control. Another pectinase (DEG 77195) was expressed $8 \log _{2}$ fold over the control. Five additional pectinase DEGs were enhanced during colonization, albeit to a lesser degree. Although Trichoderma genomes have comparatively few pectinases in relation to other CAZ and proteases, the $T$. virens genome contains pectinases capable of degrading multiple pectin architypes, indicative of the ability to colonize many different plant hosts [29-31]. Thus, the subset of pectinases enhanced in this study may represent $T$. virens response to maize on a host specific level. Morán-Diez et al. [20] also found that the pectinase 77195 was enhanced during colonization of maize roots, but not tomato roots.

Additional DEGs found significant during T. virens colonization of maize were: four arabinofuranosidases, two cutinases, two cellulases, two laccases, ten chitinases, and three enzymes which degrade complex, branched glucans. The number of CWDE expressed by T. virens may seem redundant [32]: however, research 

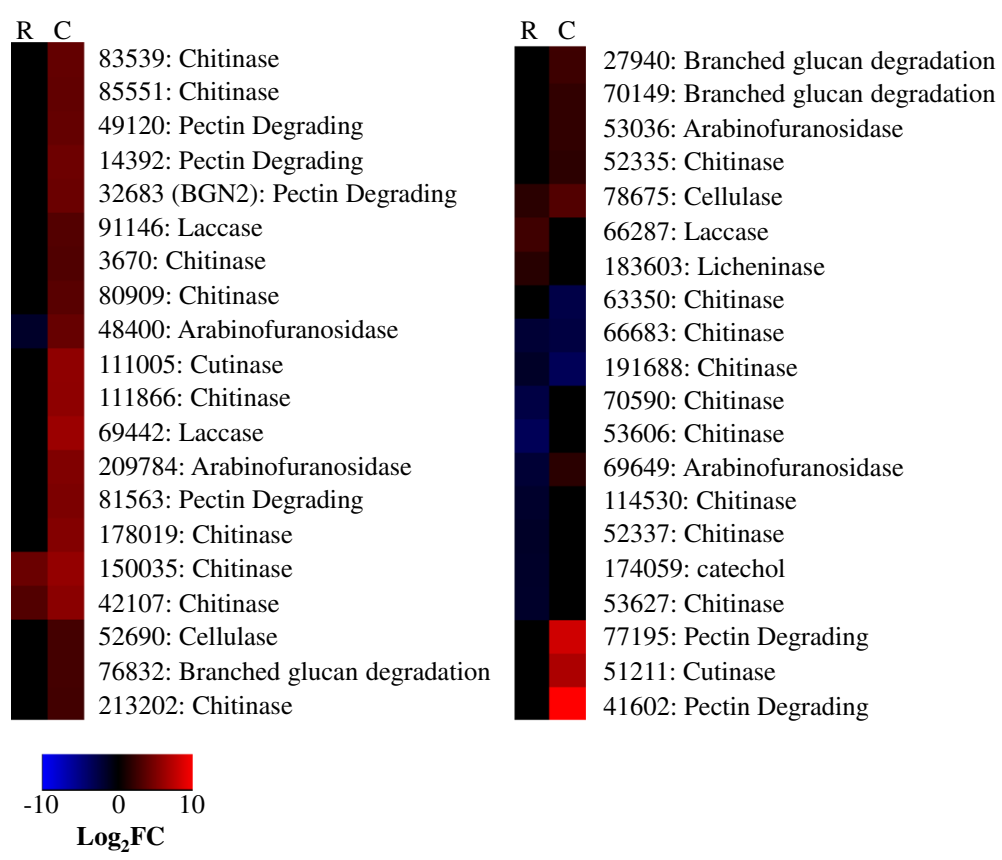

Fig. 2 Heatmap of cell wall degrading enzymes. Heatmap compares the $\log _{2}$ fold change for a given gene during Recognition (R) and Colonization (C). Red indicates more abundant gene expression during growth with maize and blue indicates less abundant gene expression. Black indicates a gene not considered significant in our analysis. Labels give the T. virens Gv29-8 gene number as annotated the JGl database version 2 and the predicted gene function

has shown that breakdown of plant cell walls is a synergistic process involving many degrading enzymes [22]. Indeed, Margolles-Clark et al. [33] presented evidence that plant cell wall substrate will provoke expression of cellulases and hemicelluloses to a differential extent, providing evidence that break-down of plant cell wall is a tightly regulated multi-component processes.

Phytohormone-like biosynthetic DEGs The influence of $T$. virens on host phytohormones has been much studied. While the molecular mechanisms remain a mystery, multiple studies have correlational evidence that $T$. virens stimulates a shift in phytohormone production. A model is emerging where Trichoderma spp. need to limit salicylic acid (SA) production to colonize plant roots [10], and subsequently boost jasmonic acid (JA) [11]. Interestingly, other endophytic fungi also repress plant SA production and have strain-dependent effects on JA [9]. Fungal effectors seem to play a large role in the mediation of SA/JA as application of $T$. virens spores versus filtrate to a plant hosts results in differential induction of SA or JA [12, 34]. Most research on T. virens mediation of phytohormone levels measures either the hormone level in planta or hormone-dependent gene expression as a reflection of hormone level. This study uniquely shows that, during maize colonization, $T$. virens has transcripts for genes putatively biosynthesizing or modulating phytohormones.
At Recognition two salicylate degrading genes (DEGs 228,034 and 223,757) were repressed; whereas, during active colonization of maize, the transcription of two different salicylate degrading enzymes were enhanced (DEGs 51,662 and 147,231). 51,662 was particularly highly enhanced with an abundance at $10 \log _{2}$ fold more than the control. At Colonization 7 DEGs encoding JA biosynthesis enzymes were enhanced (Fig. 3). Of these genes, two (DEGs 68272 and 61327) were repressed at Recognition, indicative of repression of JA biosynthesis. We also note the transcription of a precursor to ethylene synthesis (DEG 66237) during Colonization. Further, there may be effects on indole-3-acetic acid (IAA), an auxin related to plant growth and development. Three nitrilases were enhanced DEGs which have the potential to produce an IAA precursor, indole-3-acetonitrile (Fig. 3).

Oxylipin biosynthetic DEGs Association with maize prompted alternate expression of several oxylipins by $T$. virens. Note that many of the genes annotated as potentially being involved with oxylipin synthesis are unspecified monooxygenases or P450 CYP2 sub-family cytochromes. Their role in specific oxylipin synthesis will need to be verified by further research. Such research will be important to further unravel Trichoderma-plant interaction as oxylipins are prominent candidates for inter-kingdom signaling molecules [35] Lineolate acid epoxide derivatives have been shown to 
R C

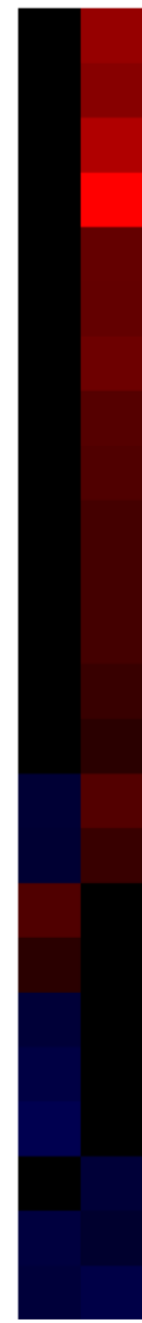

57245: nitrilase

48835: JA biosynthesis

194445: JA biosynthesis

51662: salicylate degrading

42254: nitrilase

191817: ethylene precursor

147231: salicylate degrading

66237: ethylene precursor

127285: ethylene precursor

229332: JA biosynthesis

67727: JA biosynthesis

230724: JA biosynthesis

50177: JA biosynthesis

50461: JA biosynthesis

53497: ethylene precursor

68727: JA biosynthesis

189546: nitrilase

79625: GABA

61327: JA biosynthesis

228034: salicylate degrading

223757: salicylate degrading

29989: salicylate degrading

127355: indoleamine 2,3-dioxygenase

191945: indoleamine 2,3-dioxygenase

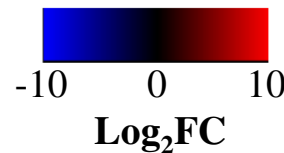

Fig. 3 Heatmap showing alternative regulation of genes involved in plant hormone synthesis / degradation. Heatmap compares the $\log _{2}$ fold change for a given gene during Recognition (R) and Colonization (C). Red indicates more abundant gene expression during growth with maize and blue indicates less abundant gene expression. Black indicates a gene not considered significant in our analysis. Labels give the T. virens Gv29-8 gene number as annotated the $\mathrm{JGl}$ database version 2 and the predicted gene function

be involved in anti-fungal defense mechanisms, crosstalk between fungi and their plant hosts, and in JA biosynthesis [35-38]. Our analysis identifies 15 DEGs involved in lineolate acid metabolism. Arachidonate acid metabolism is another venue for oxylipin production, synthesizing HETE and DHET oxylipins. This study identifies 17 DEGs as potential producers of 20-HETE, 19(S)-HETE， 16(R)-HETE，11,15,15-THETA, 11,12,15THETA, 14,15-DHET, 11,12-DHET, 8,9-DHET, and/or 5,6-DHET (See Additional file 3: Data file S2; Oxylipins). DEG 190955 is of special interest as this monooxygenase has the potential to influence oxylipins production from either lineolate or arachidonate metabolism and was enhanced at both Recognition and Colonization, 3.6 and $8.7 \log _{2}$ fold, respectively.

Additional DEGs encoding putative plant-utilized compounds Six DEGs involved in 4-coumarate-CoA synthesis were enhanced during $T$. virens colonization of maize roots (Additional file 3: Data file S2). 4-coumarate-CoA is the base molecule for synthesis of many plant secondary compounds, including flavonoids, isoflavonoids, and lignans [39]. Whether this corresponded to fungal biosynthesis and/or secretion of these molecules was outside the scope of this study, but an intriguing concept. Also seen were the elevation of catechol metabolic genes. Catechol is utilized by both plants and fungi. In plants catechol oxidase is often expressed when under stress from pathogenic attack [40]. Catechol dioxygenase has been shown to be a response of the fungal pathogen, Cochliobolus heterostrophus, to plant secreted phenolics [41]. The production of catechol may also be a by-product of salicylate degradation by fungi and bacteria $[42,43]$.

Nitrogen metabolism DEGs Trichoderma spp. can enhance plant nitrogen content [12], notably when co-inoculated onto plant hosts with nitrogen fixing bacteria [44]. In this study, T. virens appeared to alter nitrogen cycling activities starting with recognition of maize roots, during which time three NmrA-like transcripts were repressed, but two nitrite/nitrate reductases (DEGs 168068 and 177810) were enhanced. During Colonization two NmrA-like genes were enhanced (DEGs 50993 and 191851), while one was repressed (DEG 68935). Two nitronate monooxygenases were also enhanced (DEGs 47961 and 55583). Interestingly, there may have been some disfavor of nitric oxide at Colonization; both a nitric oxide dioxygenase (DEG 83817) and a nitric oxide synthase (DEG 61018) were repressed (Fig. 4). These genes could indicate repression of internal nitric oxide; however, Gupa et al. [45] demonstrated that T. asperelloides suppresses plant host nitric oxide levels in response to Fusarium attack. We speculate that $T$. virens, also has the potential to modify plant nitric oxide levels.

\section{Environmental interactions}

Defense-related DEGs The plant biome is a competitive environment, particularly the rhizosphere which hosts a 


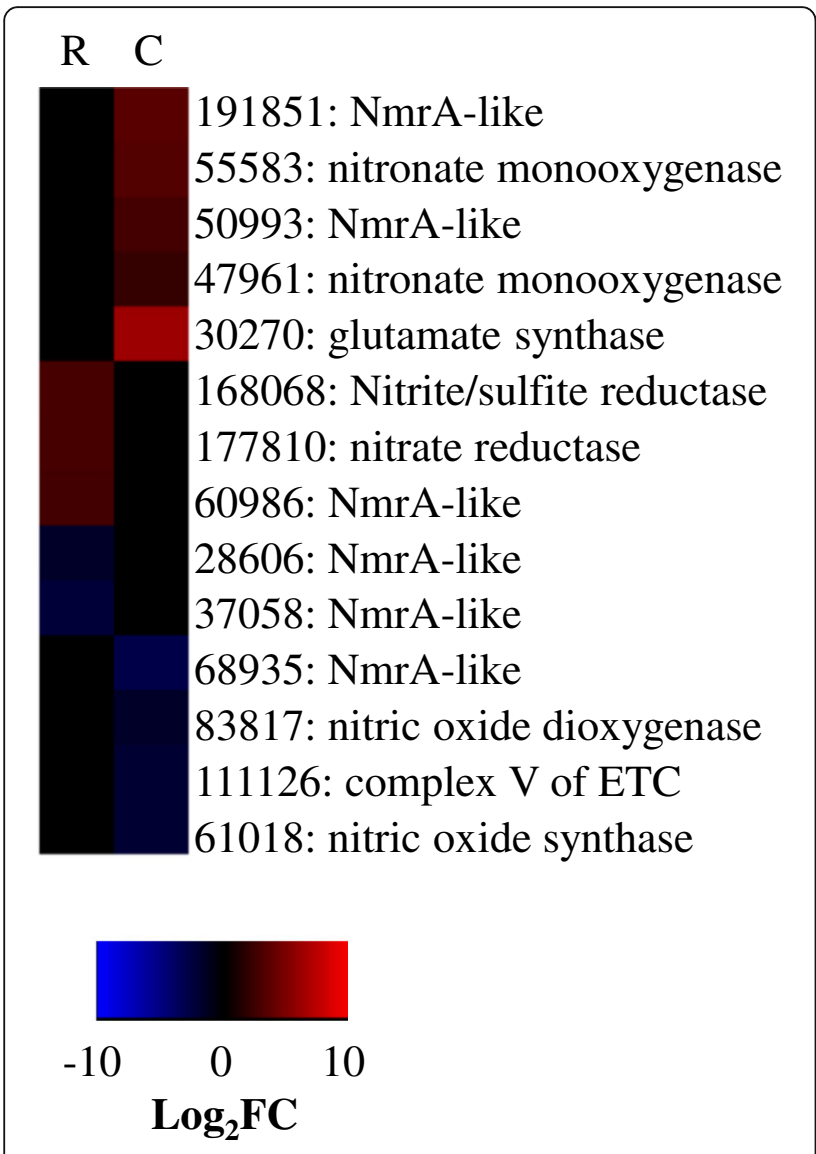

Fig. 4 Heatmap of nitrogen activities. Heatmap compares the $\log _{2}$ fold change for a given gene during Recognition (R) and Colonization (C). Red indicates more abundant gene expression during growth with maize and blue indicates less abundant gene expression. Black indicates a gene not considered significant in our analysis. Labels give the T. virens Gv29-8 gene number as annotated the JGl database version 2 and the predicted gene function

plethora of competing microorganisms. This study, however, was conducted in a hydrophobic environment where competition was lacking. Despite this four putative Defense DEGs were enhanced during Recognition: catalase (88881), a glutathione-S-transferase (231671), an arsenic resistance protein (194498), and finally a DEG with a putative stress A/B barrel domain (34890). Both an iron permease (DEG 195287) and a ferric reductase were enhanced, and a gene predicted to remove iron from siderophores (DEG 147314), suggestive that $T$. virens initiation of iron-scavenging is stimulated by maize roots and not rhizosphere competition. Other metal transporters were affected as well; a Ni transport gene was enhanced, while a zinc transporter and a heavy metal transporter were repressed. While we did not expect to see evidence for increased antibiotic expression in the sterile hydroponic system, it was also unexpected that six beta-lactamases and five DEGs predicted to function in drug metabolism/transport were repressed in the presence of maize roots (Fig. 5). Conversely, at Colonization, antibiotic metabolism and production of anti-microbial compounds may be increased. This was evidenced in the elevation of DEGs involved in isoquinoline biosynthesis, beta-metallo-lactamases, fungalysins, and drug transport and resistance (also see Secondary Metabolite section). Additionally, DEGs were enhanced which indicate expression of conotoxin, colicin, and a cyanovirus-targeted toxin. Trichoderma spp. are well known to be resistant to many toxins [46], but the secretion of toxins in planta is less studied.

Reactive oxygen species (ROS) were likely prominent in the in planta environment as T. virens enhanced 16 glutathione-metabolism genes, 4 catalases, and 1 peroxidase. Note that 2 peroxidase genes were repressed (Fig. 5, Additional file 3: Data file S2). ROS are common in plant stress signaling (reviewed in ref. [47]), and plant defense systems [48-50]. ROS burst can also occur when a symbiotic microorganism colonizes a plant host, as noted by Santos et al. [51] with alfalfa and Sinorhizobium meliloti. Trichoderma spp. can help plants alleviate heavy-metal induced ROS accumulation by expression of glutathione enzymes [7, 52-54]. We hypothesize therefore that the expression of glutathione metabolic genes by $T$. virens in maize could serve a dual role of self-protection and plant health promotion.

Secondary metabolite production DEGs Trichoderma spp. produce a plethora of secondary metabolites, both of high (peptaibols) and low (ETPs, terpenes, steroids and polyketides) molecular weight, and their genomes are rich in genes related to secondary metabolites biosynthesis and transport [1]. These secondary metabolites have widely-acknowledged roles in influencing plant growth, development, and disease resistance $[2,18,55-$ 57]. To conduct a comprehensive analysis of regulation of secondary metabolism-related genes and gene clusters during interactions of Trichoderma with roots, we created a database by identifying nearly all the genes putatively involved in secondary metabolism biosynthesis in T. virens (Additional file 5: Data file S3). This database of genes is unique in our analysis in that more genes were affected during Recognition than Colonization, although the trend of the majority of DEGs being repressed during Recognition was conserved. Note, since we wanted to capture any change in a gene cluster, we considered a gene significant if the $\mathrm{p}$-adjust value was $<$ 0.05 , regardless of whether the $\log _{2}$ fold change was \pm 1.5 . Below we discuss which specific non-ribosomal peptide synthases (NRPS), polyketide synthases (PKS), and other secondary metabolites gene clusters were found significant in this analysis (Fig. 6).

The tex 1 gene cluster, synthesizing an 18-residue peptaibol, was repressed during the Recognition phase. This 


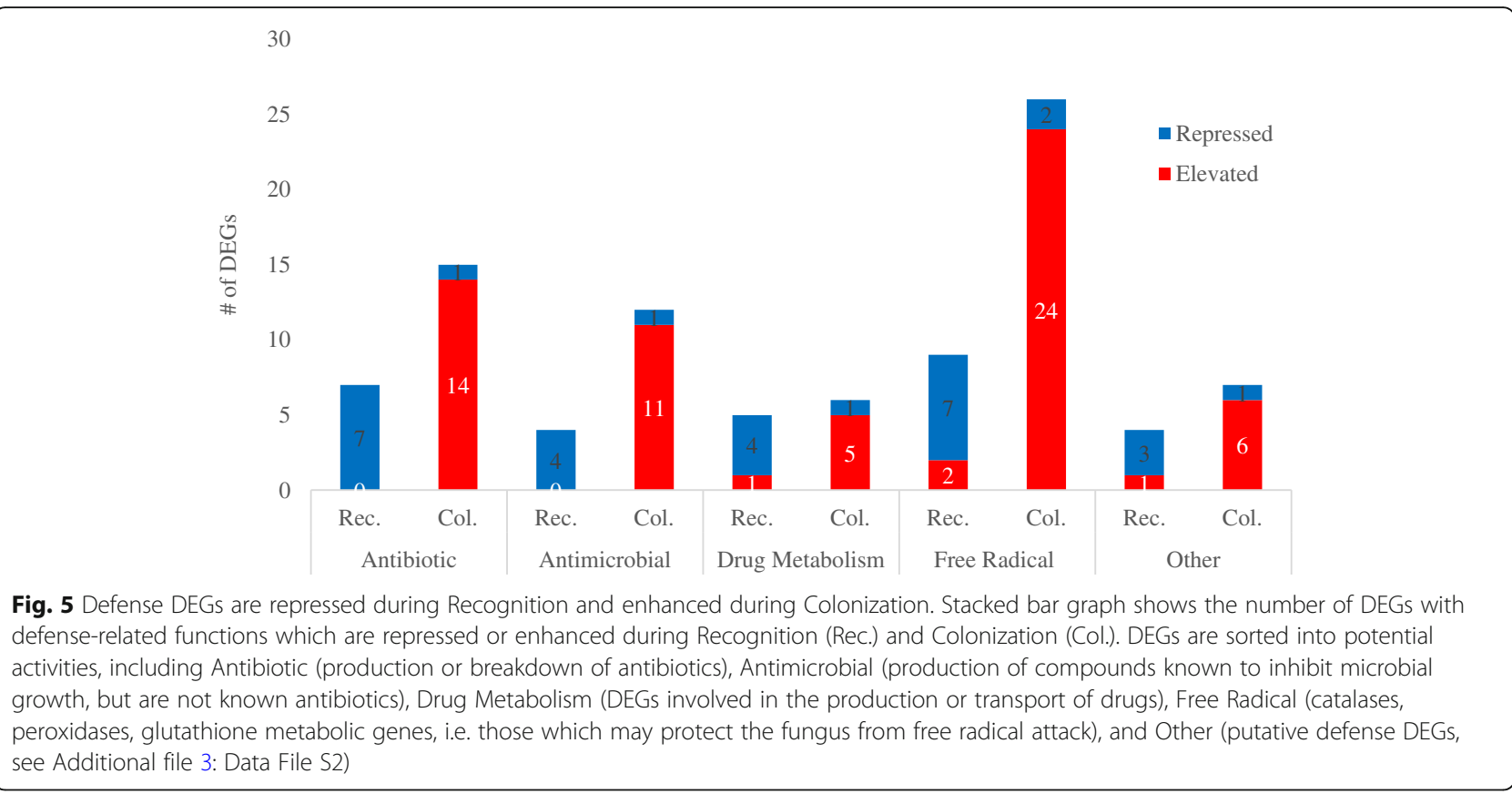

was unexpected; Viterbo et al. [17] demonstrated that tex 1 was expressed in association with cucumber seedlings and is involved in triggering ISR. During Colonization tex1 reverted to basal level expression. Induction of the tex 5 cluster during Colonization was inferred by the very strong expression ( $5 \log _{2}$ fold) of two genes in this cluster: an aldo-keto reductase (DEG 219641) and an isopenicillin N synthase family oxygenase (DEG 72869). While two of the tex5 cluster genes were repressed during Recognition this was only a mild effect, thus we hypothesize that tex5 mainly functions during the Colonization phase. The tex 6 gene cluster was mostly repressed during Recognition. Both tex5 and tex6 NRP's have unknown products; this analysis is the first to suggest a role for them in fungal-plant interactions. For tex6 the repression during Recognition suggests a role in antagonistic activity. One gene in the tex7 cluster was enhanced during Recognition, but all three genes were enhanced during Colonization. Tex7 putatively codes for a 5-residue NRP. The tex 12 cluster is a NRSP-PKS hybrid. Like the tex5/6 clusters, the product is unknown (Fig. 6a).

The tex18 cluster is more commonly known as the gliotoxin biosynthesis cluster. Gliotoxin is an ETP compound copiously secreted by $T$. virens [58]. Typically, gliotoxin is strongly expressed for $16 \mathrm{~h}$ in fresh culture and can be detected in culture media for up to $48 \mathrm{~h}$ [58]. At Recognition (6h of co-cultivation with maize) the cluster was very strongly repressed, with every gene in the cluster being less abundant in the presence of maize. At Colonization ( $30 \mathrm{~h}$ of co-cultivation) all but two genes in the cluster were significantly enhanced (Fig. 6b). Trichoderma "Q" strains are characterized by their production of gliotoxin while Trichoderma "P" strains produce another ETP, gliovirin. Our analysis detected strong elevation of expression of a remnant of the gliovirin cluster during Colonization. This gliovirin remnant cluster has 7 of the putative gliovirin biosynthesis genes, but lacked the main non-ribosomal peptide synthesis gene (Fig. 6b).

Among the PKS's, cluster 6 was strongly repressed during Recognition. During Colonization the PKS 4 cluster was enhanced. This cluster biosynthesizes conidial pigments in $T$. virens. This was intriguing as under these growth conditions, $T$. virens should not have conidated. However, this gene has also been found to be responsible for general regulation of other PKSs and stress tolerance in T. reesei [59]. Indeed, PKS cluster 8 was also enhanced during Colonization; it is possible that the elevation of PKS4 functioned to regulated PKS 8 expression (Fig. 6c).

Recently a cluster of 21 genes, responsible for synthesizing viridins, was uncovered [60]. Viridin is rapidly converted to viridiol, a phytotoxic agent [60]. Of the 21 gene cluster, 14 were significantly repressed during Recognition (Fig. 6d). During Colonization only two viridin genes were enhanced; none were repressed. We speculate that $T$. virens production of viridin may be perceived by the maize roots as a damaging agent.

Small secreted cysteine-rich proteins (SSCP) DEGs $T$. virens secretes many proteins, termed effectors, which function in $T$. virens bio-control abilities [16, 21]. Our analysis returned 55 SSCP (small secreted cysteine rich protein) DEGs, which were expressed considerably 
A

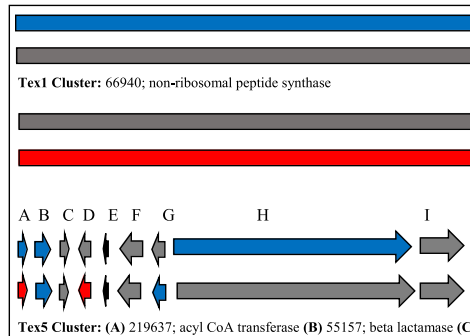

Tex5 Cluster: (A) 219637; acy CoA transferase (B) 51 5157; beta lactamase (C) 31831; UbiA prenyltransferase

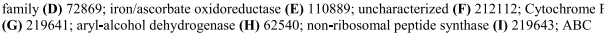
transporter

A BC DE F G H I J K L

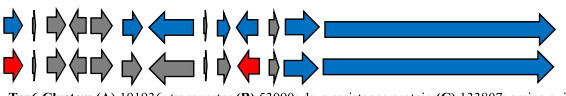

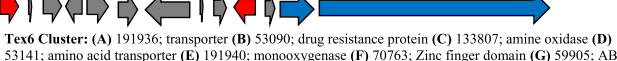

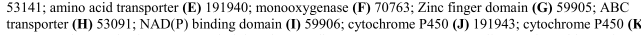

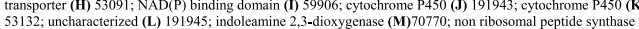

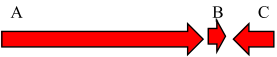

Tex7 Cluster: (A) 68467; non-ribosomal peptide synthase A B C DE F G H I J K L M N

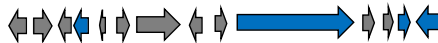

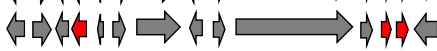

Tex12 Cluster: (A) 68779; transcription factor (B) 47764; monooxygenase (C) 68777; alpha/beta hydrolase (D) 20980, dehydrogenase (E) 48208; oxidoreductase (F) 193168; Cytochrome P450 (G) 155466; 6y7tochrome P450 (H) 47972; uncharacterized (I) 48208; cnoyl-1ike reductase domain (J) PKS-NRPS (K) (N) 47744; ; transcription factor

B

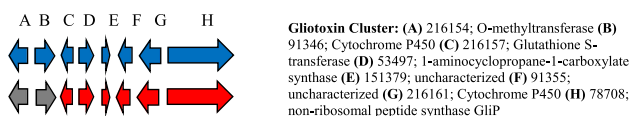

A B CD E F G

새새디대대내

새매대대대

Glioviridin Remanent Cluster: (A) 230775; uncharacterized (B) 213071;
uncharacterized (C) 151465; O-methyltransferase (D) 191816; Cytochrome uncharacterized (C) 151465; O-methyltransferase (D) 191816; Cytochrome
P450 (E) 191817; 1-aminocyclopropanc-1-carboxylate synthase (F) 213072 O-methyltransferase (G) 170504; unche-1-carboxy

C
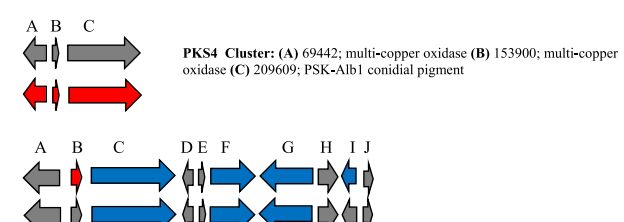

S66 Cluster: (A) 217347; Tex23 (B) 62548; GALA and AfR domain-containing protein (C) 62549; PKS (D) 140688; DUF3328 domain-containing protein (E) 62551; hypothetical (F) 34120; ABC-type bacteriocin/lantibiotic exporters (G) 187765; ABC-type bacteriocin/lantibiotic exporters (I) 140693;

\section{A B C D E F G H I}

(A山)

(1)

PKS8 Cluster: (A) 86174; gfo/dh/MocA family oxidoreductase (B) 215195; Dihydrodipicolinate synthase

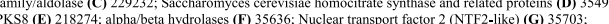
Transferase family (H) 197528; hypothetical protein (I) 188499; Fungal trichothecene efflux pump (TRI12)

D

A B C D E FGH I J K L MNOPQR R S T U

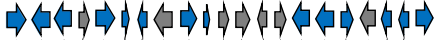

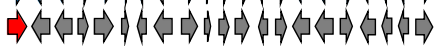

Viridin Cluster: (A) 53366; Cytochrome P450 (B) 53375; Cytochrome P450 (C) 230790; Cytochrome P450 Viridin Cluster: (A) 53366; Cytochrome P450 (B) 53375; Cytochrome P450 (C) 230790; Cytochrome
(D) 53368 ; uncharacterized (E) 170440; FAD binding (F) 78735; uncharacterized (G) 151220; carbonyl (D) 53368; uncharacterized (E) 170440; FAD binding (F) 78735; uncharacterized (G) 151220; car
reductase (H) 53690; ; ytochrome P450 (I) 230740, querectin 3-O-methyltransferase (J) 151142;
uncharacterized (K) 151341; Arylacetamide deacetylase (L) 135139; MFS transporter (M) 70971; uncharacterized (K) 151341; Arylacetamide deacetylase (L) 135139; MFS transpotter (M) 70971;
uncharacterized (N) 53581; glycoxylase (O) 53582; monooxygenase (P) 151337; Cytochrome P450 (Q)
91392; dehydrogenase (R) 128161; FAD binding domain (S) 151179; Dehydrogenase (T) 78733; uncharacterized (U) 216144; monooxygenase
Fig. 6 Gene Clusters involving (a) NRPS, (b) Gliotoxin, (c) PKS and (d) Viridin. Top row of arrows represents gene expression at Recognition, bottom row represents gene expression at Colonization. Red arrows indicated an enhanced $\log _{2}$ fold change, blue a repressed $\log _{2}$ fold change, and gray a non-significant $\log _{2 f} \mathrm{Old}$ change

differently between the Recognition and Colonization phases (Fig. 7). Among these SSCP's were two genes identified in previous research: MRSP1 (DEG 45236) and SM2 (DEG 111830); both were enhanced during Colonization. MRSP1 is a SSCP negatively regulated by a MAPK protein [61], TmkA. TmkA mutants are impacted in some mycoparatism activities [62]. MRSP1 may thus have some impact on $T$. virens direct bio-control properties. SM2 is a paralog of the well-studied SM1, a known trigger of plant induced system resistance (ISR) $[16,63]$. SM2 may have a different function in stimulating plant defense than SM1. Research has shown that $T$. virens $s m 2$, not SM1, is involved in induced defense against the maize pathogen Cochliobolus heterostrophus. It appears that SM1 activates SA-mediated response against biotrophs and hemi-biotrophs while SM2 triggers JA-mediated defense against necrotrophs [64]. As SSCPs may be potent effectors of plant defense [65] those SSCP DEGs constitutively affected during $T$. virens - maize co-cultivation were of interest. Three of these were continually repressed (DEGs 86324, 92434, and 211280). DEG 86324 is annotated as $\mathrm{pH}$ responsive and potentially affecting transcription factor activity. DEGs 92434 and 211280 are uncharacterized beyond putative SSCPs. One DEG (32996, having a lysozyme-like superfamily domain) was continually enhanced. DEG 93159 is annotated only as a putative SSCP and was oppositely regulated, being repressed $-2.0 \log _{2}$ fold at Recognition and enhanced 7.2 $\log _{2}$ fold during Colonization.

Organismal morphology and mating DEGs Shift from growth in liquid nutritive medium to in planta growth likely stimulates morphological change in $T$. virens. Upon $T$. virens recognition of maize roots this change is neither physically nor genetically evident; hyphae growing towards maize roots retained their filamentous appearance. During the Colonization phase, however, four genes predicted to have a role in actin-based cell structures were enhanced, as well as two actin cross-linking DEGs. It has been shown before that $T$. harzianum switches to a yeast-like morphology inside Arabidopsis roots [9] thus $T$. virens may do the same.

$T$. virens recombinant strain potential was affected by either co-cultivation with maize or exposure to the seed-borne endophytic maize microbiome, evidenced by the numerous heterokaryon incompatibility DEGs. At 


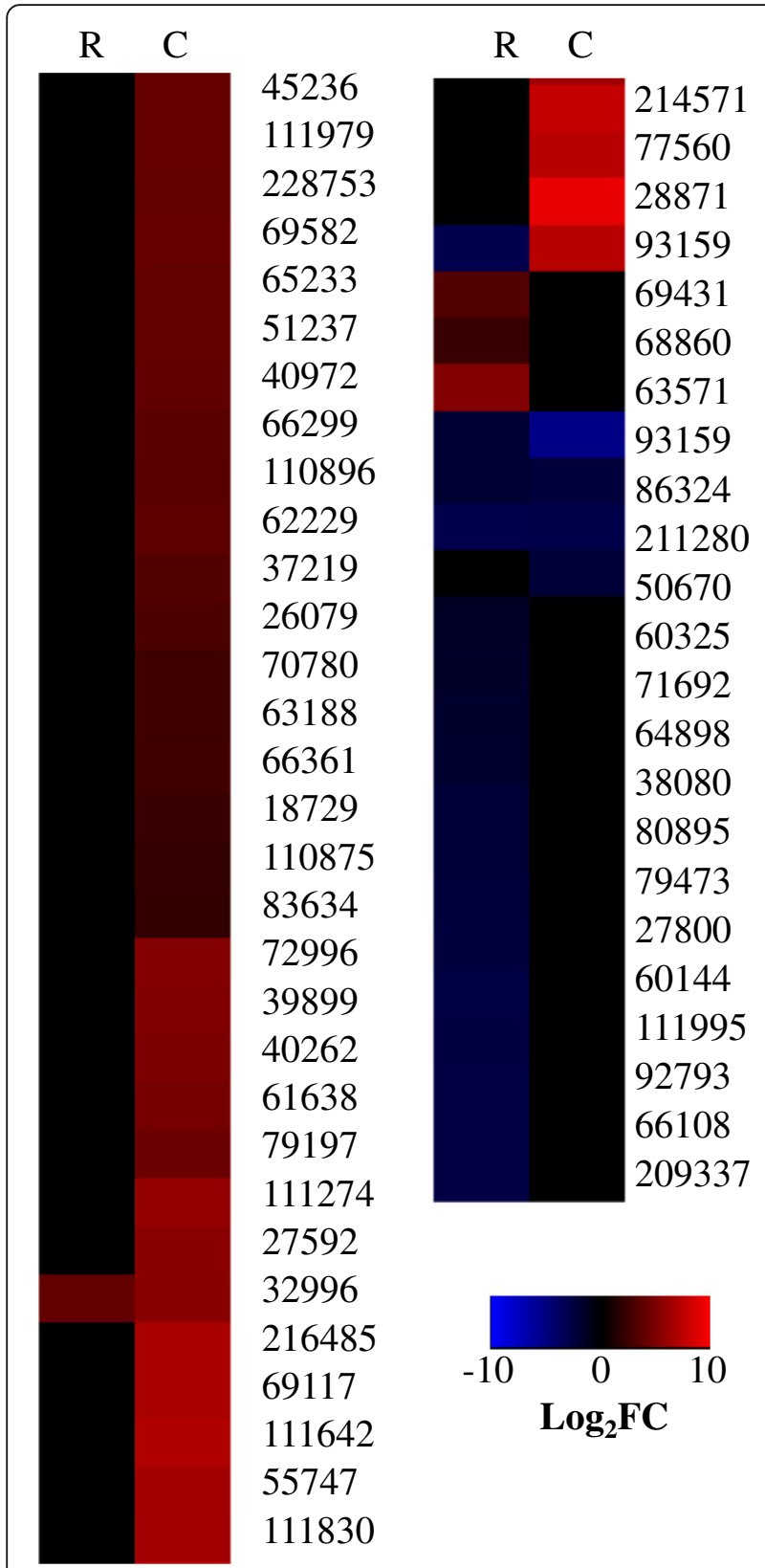

Fig. 7 Heatmap compares the $\log _{2}$ fold change for a given gene during Recognition (R) and Colonization (C). Red indicates more abundant gene expression during growth with maize and blue indicates less abundant gene expression. Black indicates a gene not considered significant in our analysis. Labels give the T. virens Gv298 gene number as annotated the JGI database version 2; all genes are putative SSCP's

Recognition $T$. virens repressed 11 heterokaryon incompatibility proteins. Further, two genes annotated as both an oligopeptide transporters and sexual differentiation proteins, 189,327 and 84,303, were DEGs. During $T$. virens Colonization of maize 13 different heterokaryon incompatibility genes were enhanced, while two were repressed (Additional file 3: Data file S2).
Extracellular structures and Cell Wall remodeling DEGs T. virens extracellular structures appeared to undergo swift remodeling starting upon exposure to maize roots and continuing through colonization. 31 extracellular / cell wall DEGs were found during Recognition and 53 during Colonization (Additional file 3: Data file S2). These genes represent hydrophobins, glycoprotein-associated, cell wall structures, adhesions, and glycolipid/glycophospholipid metabolic genes. Fungal cell wall and extracellular structures often mediate the initial fungal-microbe interaction [26-28, 38, 66]. The DEGs identified here will require additional empirical analysis to determine their roles in plant attachment and/or suppression/evasion of plant defenses.

Hydrophobin DEGs were highly impacted within this functional category. Three hydrophobin-like genes were repressed at Recognition; two were ceratoulimins (DEGS 83985 and 9842), and the other (DEG 45185) was a lipocalin predicted to bind hydrophobins. One predicted hydrophobin was enhanced during Recognition, as was a putative extracellular protein (DEG 68031). During Colonization seven different hydrophobin encoding transcripts were enhanced. Although the highest number of extracellular DEGs were glycoproteins, DEGs annotation as being hydrophobins or hydrophobin-like had the greatest $\log _{2}$ fold change in the differential expression analysis (Fig. 8). TvHFB9a (DEG 121648) and DEG 49849 were extremely enhanced; 10 and $9 \log _{2}$ fold, respectively. TvHFB9a has been tied to research demonstrating that hydrophobins can contribute to a protein biofilm layer on the fungal surface [67]. This protein layer was suggested by Bonazza et al. [67] to maintain moisture; however, hydrophobins have been shown to be critical in plant colonization and during abiotic stress for many fungi $[8,68,69]$. The failure of fungal hydrophobin mutants to colonize plant roots may be a structural issue - hydrophobins affect aerial hyphal growth as well as absorption to surfaces [28, 67, 70]. Askolin et al. [70] reported that two $T$. reesei hydrophobins, $h f b 1$ and $h f b 2$, could not complement each other. Thus the 15 hydrophobin genes identified in our analysis cannot be assumed to have had redundant functions.

Of special interest were nine DEGs annotated as beta-1,6-N-acetylglucosaminyltransferases. These molecules directly modify the glycans present on the cell wall, which can serve as MAMP/PAMPS (Microbial or Pathogen Associated Molecular Patterns) recognized by the plant host [71]. Three of these transcripts were repressed at Recognition, possibly indicating evasion of host defense. DEG 216297 was continually repressed into Colonization as well. Further, two DEGs with LysM domains were repressed (DEG 222410) and enhanced (DEG 120125) during Colonization. These DEGS may have aided in fungal colonization by masking chitins 


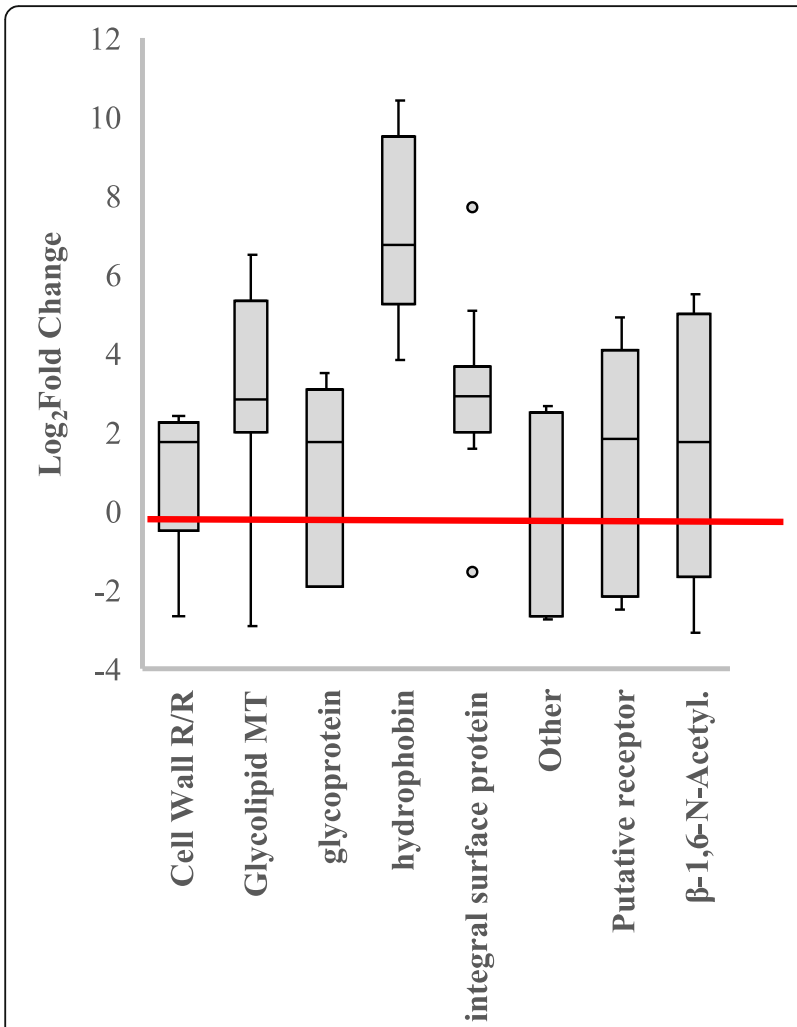

Fig. 8 Hydrophobins were highly enhanced during Colonization. Box plot of the range of $\log _{2}$ fold change for extracellular and cell wall structures during Colonization. Key; R/R = Replication and Repair; MT = Metabolism and

Transport; $\beta-1,6-\mathrm{N}$-Acetyl $=\beta-1,6-\mathrm{N}$-Acetyltransferase

which would otherwise act as plant defense elicitors [72, 73].

Cell membrane remodeling DEGs There was extensive evidence for the remodeling of cell membrane at $T$. virens recognition of maize roots. At Recognition 28 DEGs predicted to influence cell membrane were identified (Fig. 9). 20 of these DEGs were repressed. At Colonization 49 such DEGs were identified with 42 of these being enhanced (Fig. 9). DEGs predicted to influence cell membrane structures encoded membrane ankyrin repeat domains, phospholipases, permeases, integral membrane proteins, and channels / membrane anchoring or transport proteins. Of interest were two DEGs, repressed at Recognition, which are predicted to function in periplasmic transport and have DSBA domains. These domains can play a role in virulence, toxins, motility, and/or adhesion in bacterial pathogens [74]. We hypothesize repression of these genes resulted in outer membrane composition remodeling to evade triggering of host defenses prior to colonization. During the colonization phase we noted that six voltage gated $\mathrm{K}$ + channel transcripts were enhanced. These may not have influenced membrane structure but do indicate remolding of membrane permeability (Fig. 9).

\section{Impact on fungal internal processes}

$T$. virens extracellular changes must be driven by internal genomic processes. For DEGs functioning in genomic functional groups such as Translation and DNA Repair/Replication, little change was noted. Several DEGs were altered which function in Transport and Vesicle formation, but these genes will have to be empirically studied to understand their function as well as the ten heat shock proteins repressed during Recognition (Additional file 3: Data file S2). Vast alterations were seen, however, in Transcription factors, Signal Transduction, and Post-Transcriptional/Translational Modification. These are described below.

Transcription factor DEGs 95 putative transcription factors were significant in our analysis between both fungal phases. The regulon of many of these transcription factors is unknown. Three DEGs were noted which belong to the Myb superfamily (DEGs 67860, 9220, and 130839). This superfamily of transcription factors is often active in plant development [75]. Four transcription factors had DEAD-box motifs, indicating potential involvement in RNA metabolism [76] (Additional file 3: Data file S2).

Signal transduction mechanism DEGs $T$. virens underwent re-programming of the signal transduction transcriptome within $6 \mathrm{~h}$ of co-cultivation with maize roots (Fig. 10). At the Recognition phase 35 DEGs were identified which had putative roles in signal transduction. Nine serine/threonine kinases (STK) were identified; four of which were also DEGs during Colonization (DEGs 117,265, 217,577, 70,546, and 77,550). DEG 29675 is a putative signal transduction gene of interest as this gene codes for a PAS/PAC domain, involved in environmental sensing, and a putative DNA binding domain.

An additional six STKs were identified as DEGs specifically during Colonization of maize roots; five of these were enhanced while only one was repressed. STKs in Trichoderma are best studied in the context of MAPKs (mitogen activated protein kinases). Roles for MAPKs have been found in hyphal growth, conidiation, mycoparatism, and mediation of ISR $[4,77-79]$. Each MAPK signaling cascade appears to be specific to a particular process thus the STKs in our study could represent uniquely plant associated signal transduction mechanisms.

Another three DEGs with phosphatase domains and three receptor tyrosine kinases (RTK) with ankyrin repeat domains were also up-regulated during Colonization. Three additional signal transducing genes which bear 

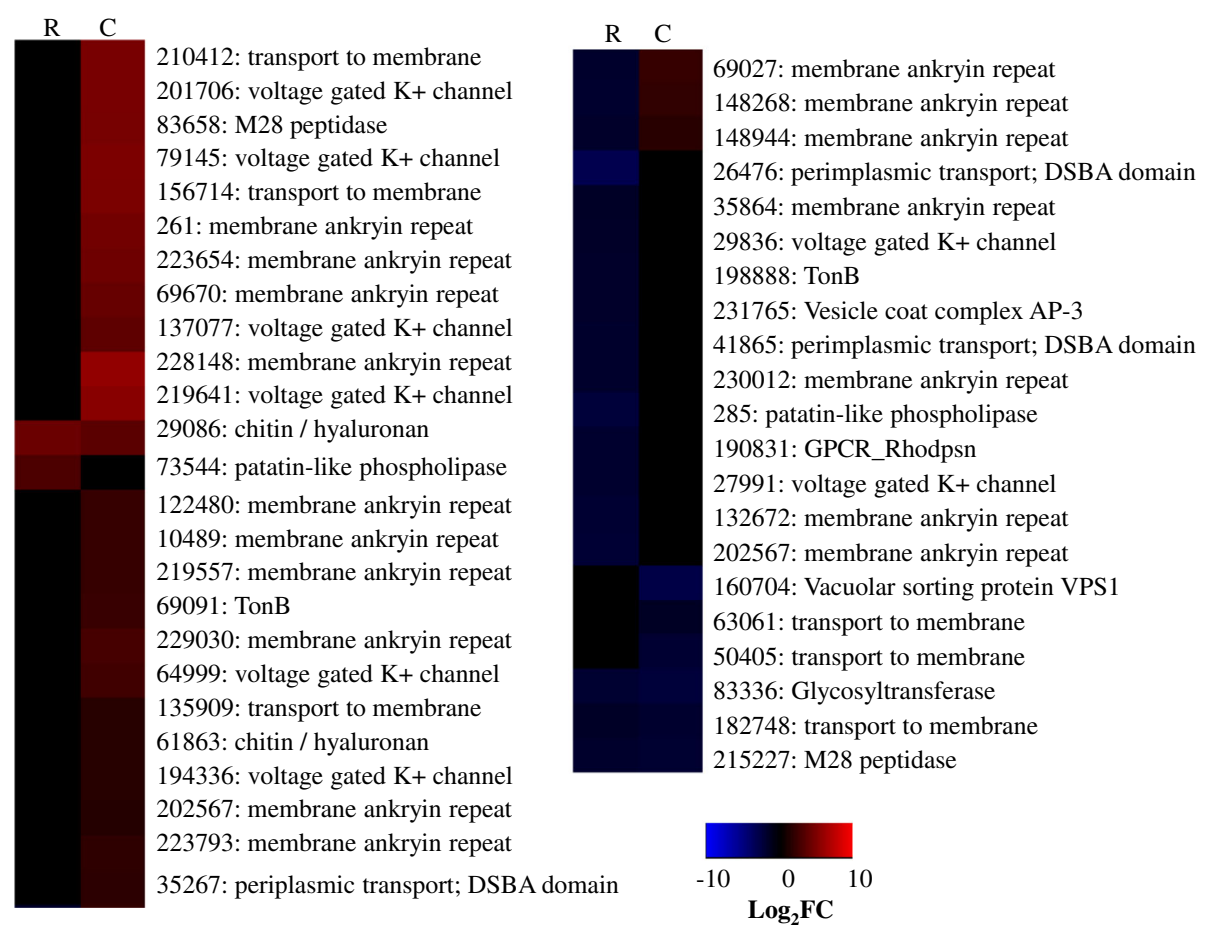

Fig. 9 Heatmap compares the $\log _{2}$ fold change for a given gene during Recognition (R) and Colonization (C). Red indicates more abundant gene expression during growth with maize and blue indicates less abundant gene expression. Black indicates a gene not considered significant in our analysis. Labels give the T. virens Gv29-8 gene number as annotated the JGl database version 2 and the predicted gene function

further scrutiny were enhanced at $T$. virens colonization; DEG 50684 is annotated as a histidine kinase response regulator, DEG 227013 has a helix-turn-helix domain suggestive of a DNA-binding response regulator, and DEG 73856 has an ENVOY domain predicted to influence genes involved in light tolerance and cellulase. Concerning genes which could be involved in environmental perception leading to internal signal replay during $T$. virens colonization, we found DEG 8714 is both predicted to be a signal transducing gene and is predicted to link proteins to the outer membrane. A signal transduction DEG with a PAS domain (30406) was one of the few repressed signal transducing genes repressed at Colonization (Fig. 10).

This study highlights calcium as an important secondary messenger during $T$. virens - maize symbiosis (Fig. 10). Calcium was previously shown to be an important signaling molecule between $T$. atroviridie and plant cells [80]. Plant cells are also known to use calcium as intercellular messengers [81]. In our study, ten signal transduction genes annotated as calcium modulated or dependent were identified as DEGs. Three of these DEGs were enhanced during Recognition; one was repressed. The remaining six DEGs were up-regulated during $T$. virens - maize Colonization, four of which belong to the EF-hand superfamily indicative of direct calcium binding. Further, three calcium transporting genes were enhanced DEGs during Colonization. Of these DEG
59192 was significantly repressed during Recognition. Three calcium dependent genes were significant in both Recognition and Colonization and thus potentially play a role in signaling for the lifestyle switch required for $T$. virens to shift from growth in nutritive liquid media to growth in maize roots: DEG 13560(a C-type lectin), DEG 53367 (a Ca2+/Na exchangers), and DEG 59192 (calcium transporting).

Post-transcriptional/translational DEGs during colon ization Not all genetic changes can be captured in an RNA-Seq analysis as transcriptional regulation does not always reflect translated proteome. Therefore, it is important to pay attention to post-transcriptional/translation processes. Two ribonucleases were highlighted in our analysis which may function in post-transcriptional modification (DEG 47489 was enhanced at Recognition and Colonization; DEG 60427 was enhanced at Colonization). During Colonization, four co-splicing activators, two genes associated with RNA silencing, a dsRNA Dicer gene, and a T2 ribonuclease were enhanced. Oddly, a single gene functioning in adding the 5' mRNA cap was repressed at both Recognition and Colonization (Additional file 3: Data file S2).

Post-translational modification occurred primarily during the Colonization phase. Only four genes which may 
$\mathbf{A}$

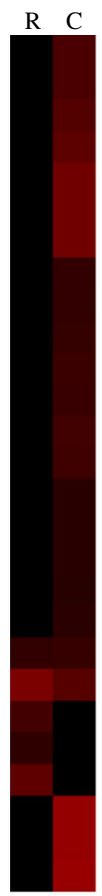

193217: Serine/threonine protein kinase 227013: Serine/threonine protein kinase 112497: RTK signaling protein MASK/UNC-44 62286: Serine/threonine protein kinase 170512: Phospholipase C

206874: Circadian clock protein

115012: Histidine kinase

84609: AChEI/BChE

48872: AChEI/BChE

112183: Serine/threonine protein kinase 220230: RTK signaling protein MASK/UNC-44 44633: AChEI/BChE

144969: Kinase-like_dom_sf

193913: Pyrv/PenolPyrv_Kinase-like_dom

38248: Calpain

215640: RhoA GTPase effector DIA/Diaphanous

68804: MEKK and related STK

55932: tyrosine phosphatase, fn3 domain

170891: Signal_recog_particle_SRP9/14

117265: Serine/threonine protein kinase

217577: Serine/threonine protein kinase

177811: Programmed cell death 8

37227: AChEI/BChE

221402: Serine/threonine protein kinase

195940: AChEI/BChE

170508: Ca2+-binding EGF-like domain

56034: AChEI/BChE

B

$\mathrm{R} C$

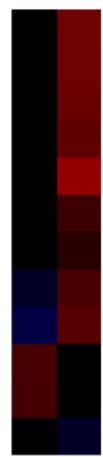

51284: Ca2+/calmodulin-dependent kinase

34827: $\mathrm{Ca} 2+$ transporting ATPase

111479: lipoprotein receptors, EGF-like

67673: Ca2+ transporting ATPase

170508: Ca2+-binding EGF-like

15704: Ca2+-modulated polycystin

38248: Ca2+-dependent cysteine protease

59192: $\mathrm{Ca} 2+$ transporting ATPase

53367: $\mathrm{Ca} 2+/ \mathrm{Na}+$ exchanger

81599: Ca2+-modulated polycystin

65042: $\mathrm{Ca} 2+-$ modulated polycystin

210318: $\mathrm{Ca} 2+$ transporting ATPase

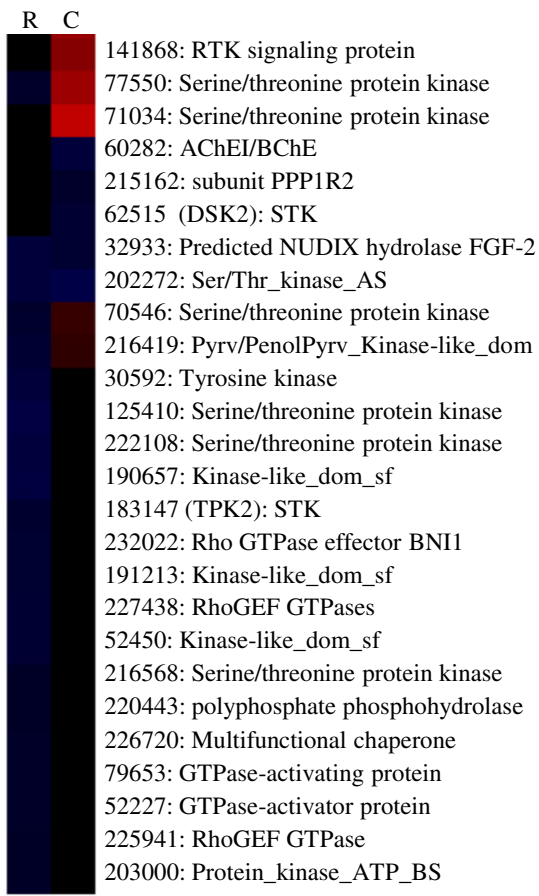

C
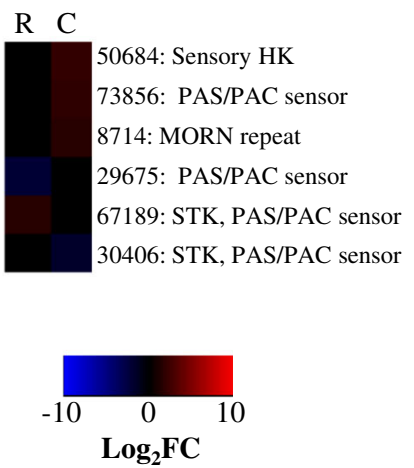

Fig. 10 Signaling DEGs are important in T. virens maize symbiosis. Heatmaps compare the log fold change for a given gene during Recognition (R) and Colonization (C). a shows putative signaling genes, b shows calcium dependent DEGs and c shows signal DEGs linked to environmental sensing. Red indicates more abundant gene expression during growth with maize and blue indicates less abundant gene expression. Black indicates a gene not considered significant in our analysis. Labels give the T. virens Gv29-8 gene number as annotated the JGI database version 2 and the predicted gene function

modify amino acid residues were DEGs at Recognition. At Colonization eleven such genes were enhanced. A further four peptidases which may cleave polypeptides and protein precursors were enhanced at Colonization as well. General protein turn-over also appeared to be increased during $T$. virens-maize colonization; four peptidases with polypeptide protein precursor cleavage activity and two genes with protein turn-over activity were enhanced. DEG 2166625 is a ubiquitin hydrolase, cleaving polypeptide bonds with less than 60 amino acid residue and was repressed at Recognition and enhanced at Colonization. This gene may function in post-translational control of small secreted polypeptides. Finally, we note the differential activity of four genes with IBR and half RING finger domains, suggestive of modulation of both protein turnover and transcriptional activity. All four were enhanced during Colonization; one was repressed at Recognition (Additional file 3: Data File S2). 


\section{Fungal metabolism and energy}

Plant-hosts provide a rich array of metabolites for fungal consumption. Consequently, many DEGs were classified as having metabolic function (Additional file 3: Data File S2). Analysis of these DEGs suggests that $T$. virens was converting plant produced sucrose to fructose or glucose and then to pyruvate (Fig. 11 and Table 1). Transcription of sucrose metabolic genes during $T$. virens - maize colonization was expected as sucrose is a key ingredient in T. virens - plant interactions [82-84]. Sucrose metabolic genes, however, were not altered until after root recognition. This would suggest that sucrose is not perceived by the fungus as an indicator of plant roots. Also unexpected was the abundance of transcripts capable of converting pyruvate into ethanol during colonization (Fig. 11). Such metabolite activity should be explored for potential in bio-fuel production.

The alterations to lipid metabolism are not as clear cut. Sphingophospholipid metabolism seems to have been enhanced during Colonization, when three ceramide synthesis DEGs were enhanced. Sphingolipids function in plant defensive systems and are well-known in plant pathogen interactions (reviewed in ref. [85]). The fate of hexadecanoyl-CoA may diverge between $T$. virens Recognition and Colonization of maize roots. Transcripts encoding hexadecanoyl-CoA synthesis were enhanced during both phases, but genes encoding enzymes for the breakdown of hexadecanoyl-CoA were repressed during Recognition (Additional file 3: Data file S2). We hypothesize that hexadecanoyl-CoA was diverted to sphingophospholipid metabolism during Recognition, supporting the initiation of membrane remodeling [86].

Sulfur metabolic processes were important during the colonization phase. This was inferred based on six DEGs in taurine metabolism, which may be catabolized under sulfur starvation conditions [87]. We also noted a highly enhanced sulfate uptake DEG (193580, $5 \log _{2}$ fold increase), and two sulfite oxidases that were very highly enhanced, 6 and $8 \log _{2}$ fold for DEGs 215055 and 231246, respectively. The need for sulfur during Colonization may simply be a consequence of protein formation, as T. virens alters its' secondary metabolite production within maize roots (see Secondary Metabolite section). This may also, however, be related to expression of the cellulases [88] that $T$. virens also utilizes during Colonization (see Plant Cell Wall Degrading Enzyme DEGs section).

Elevation of five dihydrodipicolinates (rate limiting step of lysine biosynthesis) and seven serine biosynthetic DEGs indicates a need for these two amino acids during T. virens - maize colonization. The cause for this likely lies in the translation of specific proteins, but more analysis is required.

Finally, we report that oxidative phosphorylation may have been depressed in the hydroponic maize rhizosphere which $T$. virens encountered during the Recognition phase. Eleven NADH oxidoreductases were repressed. Five of
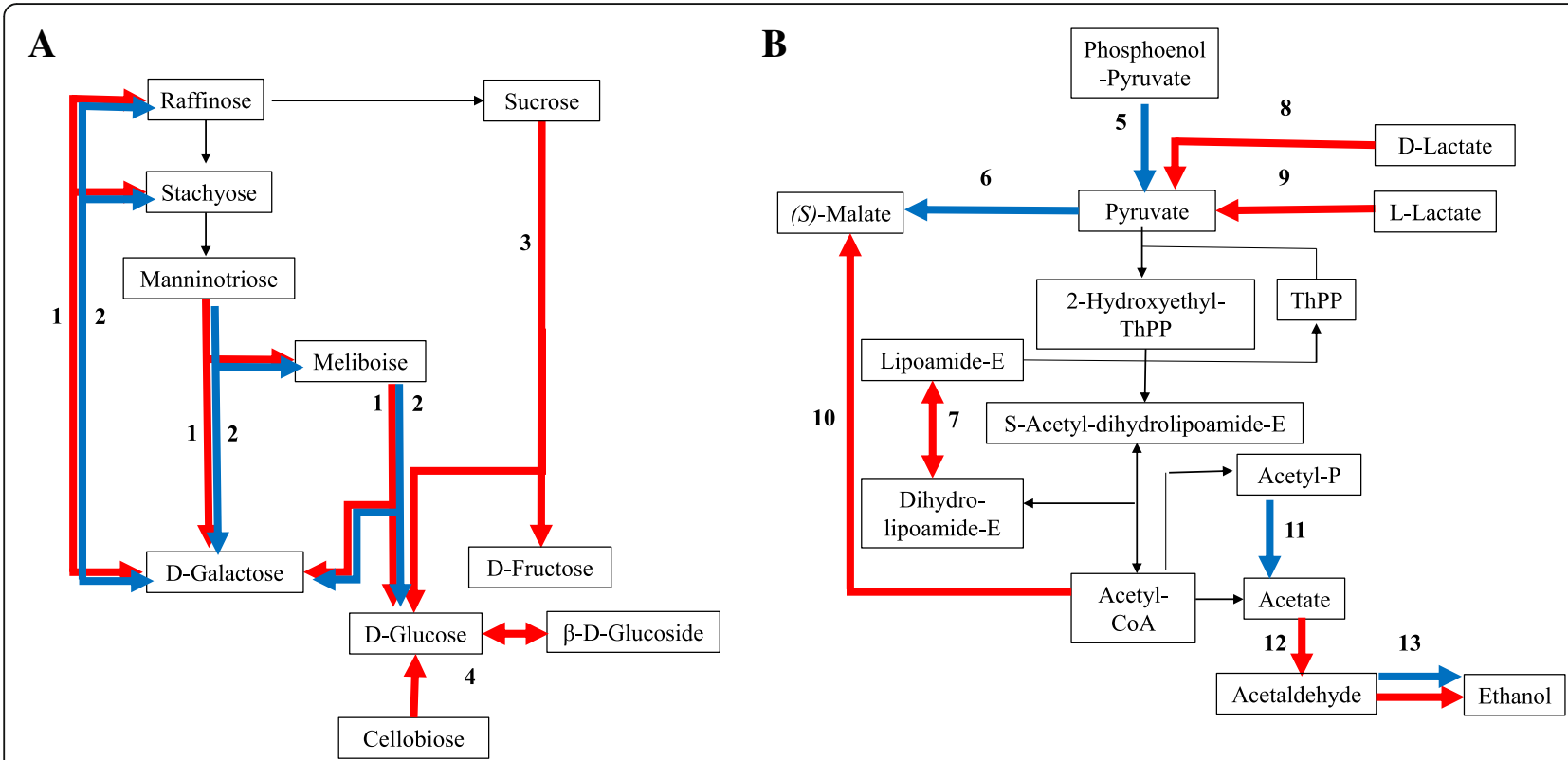

Fig. 11 Alterations in pyruvate and sucrose metabolism during Colonization. Metabolic maps show putative pathways in sucrose (a) and pyruvate (b) metabolism in Trichoderma spp. Red arrows indicate a process enhanced during the Colonization phase and blue arrows indicate repressed processes. Each process is numerically labeled. The table indicates which individual DEGs support each numbered process, their $\log _{2}$ fold change, KEGG Enzyme Class, and annotation 
Table 1 Details for gene involved in the processes highlighted in Fig. 11

\begin{tabular}{|c|c|c|c|c|}
\hline Area & Gene \# & $\log _{2} \mathrm{FC}$ & KEGG EC & Additional Annotation \\
\hline 1 & 41607 & 3.01 & 3.2.1.22 & Melibiase \\
\hline 1 & 27922 & 2.46 & - & Melibiase \\
\hline 1 & 76590 & 6.63 & - & Melibiase \\
\hline 2 & 39936 & -1.96 & - & Melibiase \\
\hline 3 & 45446 & 2.61 & 3.2.1.20 & Maltase glucoamylase, GH family 31 \\
\hline 3 & 53515 & 1.92 & 3.2.1.20 & Alpha-amylase, GH family 13 \\
\hline 3 & 48285 & 1.74 & 3.2.1.20 & Alpha glucosidase, GH family 31 \\
\hline 3 & 34797 & 5.16 & 3.2.1.20 & Alpha glucosidase, GH family 31 \\
\hline 4 & 83777 & 4.73 & 3.2.1.21 & beta-glucosidase \\
\hline 4 & 29366 & 5.83 & 3.2.1.21 & beta-glucosidase \\
\hline 4 & 41347 & 3.77 & 3.2.1.21 & beta-glucosidase \\
\hline 4 & 192759 & 2.64 & 3.2.1.21 & beta-glucosidase \\
\hline 4 & 151663 & 2.79 & 3.2.1.21 & beta-glucosidase \\
\hline 4 & 188402 & 3.39 & 3.2.1.21 & beta-glucosidase \\
\hline 4 & 58670 & 4.48 & 3.2.1.21 & beta-glucosidase \\
\hline 4 & 200358 & 6.03 & 3.2.1.21 & beta-glucosidase \\
\hline 5 & 51808 & -1.63 & 2.7.9.2 & Pyruvate, water dikninase \\
\hline 6 & 140682 & -1.83 & 1.1.1.40 & NADP+-dependent malic enzyme \\
\hline 7 & 170560 & 2.96 & 1.8.1.4 & Dihydrolipoamide dehydrogenase \\
\hline 8 & 43109 & 1.67 & 1.1.2.4 & D-lactate dehydrogenase) \\
\hline 9 & 32483 & 2.90 & 1.1.2.3 & L-lactate dehydrogenase \\
\hline 9 & 88637 & 2.56 & 1.1.2.3 & L-lactate dehydrogenase \\
\hline 10 & 89424 & 1.97 & 2.3.3.9 & Malate synthase \\
\hline 11 & 75459 & -2.05 & 2.7.2.1 & Acetate kinase \\
\hline 12 & 67893 & 5.35 & 1.2.1.3 & Aldehyde dehydrogenase \\
\hline 12 & 56585 & 4.07 & 1.2.1.3 & Aldehyde dehydrogenase \\
\hline 12 & 74949 & 1.94 & 1.2.1.3 & Aldehyde dehydrogenase \\
\hline 12 & 82254 & $2.22^{*}$ & 1.2.1.3 & Aldehyde dehydrongase \\
\hline 13 & 88512 & 5.07 & 1.1.1.2 & Alcohol dehydrogenase \\
\hline 13 & 28993 & 3.30 & 1.1.1.2 & Alcohol dehydrogenase \\
\hline 13 & 34930 & 3.26 & 1.1.1.2 & Alcohol dehydrogenase \\
\hline 13 & 78522 & 2.51 & 1.1.1.2 & Alcohol dehydrogenase \\
\hline 13 & 217031 & 2.12 & 1.1.1.2 & Alcohol dehydrogenase \\
\hline 13 & 82626 & 2.05 & 1.1.1.2 & Alcohol dehydrogenase \\
\hline 13 & 215323 & -1.82 & 1.1.1.2 & Alcohol dehydrogenase \\
\hline
\end{tabular}

these are annotated as zinc binding NADH oxidoreductases and six are specifically involved in Complex I of oxidative phosphorylation. Once T. virens had colonized the plants five of these $\mathrm{NADH}$ oxidoreductases became enhanced again, along with an addition seven different $\mathrm{NADH}$ oxidoreductase transcripts. During Colonization there was also the elevation of several phenol monooxygenases, predicted to be involved in ubiquinone synthesis (Additional file 3: Data File S2).

\section{Conclusion}

We present here the most comprehensive genomic analysis, to date, of the $T$. virens transcriptome during the recognition and subsequent colonization of maize roots. We present data which indicates that when $T$. virens first 'recognizes' the presence of maize roots the fungus represses transcription of genes across a broad spectrum of activity. We hypothesize that this is done either to avoid stimulation of plant defenses or to conserve energy required for the enhanced transcription of proteins required for root colonization. During actual colonization of maize roots, $T$. virens enhances expression of genes with a wide array of functions, including but not limited to: plant cell wall degradation, reactive oxygen species, phytohormone biosynthesis, secondary metabolites, metabolism, and signal transduction. These genes are likely necessary to facilitate the entry of $T$. virens into the maize root and persist in that altered environment. The genetic evidence presented for direct transcription of phytohormones, jasmonic acid in particular, may provide new scaffolding for unraveling the mechanisms by which $T$. virens affects plant hormone signaling. Further, we show that $T$. virens likely undergoes morphological changes within the root cortex in terms of both actin-based structure and cell wall/membrane remolding. The reason for this change is yet unknown but may reflect spatial constraints existing within the plant environment.

We anticipate that the full value of this dataset will be revealed over time as the genes identified here will provide a basis for increasingly targeted studies, in terms of microarrays, RT-qPCR, and genetic manipulation aimed at better understanding of the agronomically important symbiosis between $T$. virens and maize. Further, comparison of transcriptomic studies will push forward our understanding of plant-microbe interactions. For example, Morán-Diez et al. [20] conducted a microarray analysis comparing the transcriptomic responses of $T$. virens colonizing tomato roots versus maize roots after $72 \mathrm{~h}$. This microarray presented data that $T$. virens does, in fact, respond to different plant hosts in a transcriptionally distinct manner. Comparison with the Colonization DEGs $(30 \mathrm{~h})$ in our dataset show $30 \%$ similarity with the genes Morán-Diez et al. [20] discovered as enhanced in maize (cultivar Silver Queen). Yet we also have a $30 \%$ similarity with those enhanced in tomato (cultivar Moneymaker). A recent study by Nogueria-Lopez et al. [7] identified 43 proteins secreted by $T$. virens into maize apoplast (cultivar 34H31) after 5 days. Only five of these proteins are transcriptionally enhanced during our Colonization dataset (DEGs 215514, 74949, 29366, 71600, and 53497). All three studies (this one, 7 , and 20), however, indicate that mitigation of reactive oxygen species, abiotic stress, and production of 
glycosyl hydrolases are important in T. virens- maize interaction, even though the exact gene/protein utilized is different.

Several ideas can be extrapolated from this brief comparison. One, $T$. virens responds to plant hosts in a strain dependent manner. Two, T. virens - maize interaction is quite dynamic over time in terms of transcriptional activity and secreted proteins. Three, the overall mechanisms of plant interactions are conserved between plant hosts and individual genes have adapted to specific hosts. To validate these hypothesizes rigorous meta-analysis is needed of 'omics data on $T$. virens maize interactions. This requires more published data in terms of $T$. virens-maize association, on a strain level and with respect to hours/days of colonization. Such information will greatly enhance bio-engineering of bio-control strains to specific hosts and development of Trichoderma based enzymes for specific purposes.

\section{Methods}

\section{Hydroponic set-up}

B73 wild-type maize seeds used in this study were locally grown and provided by Dr. Kolomiets.

The wild-type strain (Gv29-8) of T. virens was isolated from a sandy loam soil cultivated with cotton plants in Texas and is deposited at the Fungal Genetics Stock Center, with genome sequence and annotation available at the JGI portal, version 2 (https://genome.jgi.doe.gov/ TriviGv29_8_2/TriviGv29_8_2.home.html). Prior to placement of maize seedlings in the hydroponic system, the seeds were sterilized with a $70 \%$ ethanol wash for 5 min and then with a $10 \% \mathrm{H}_{2} \mathrm{O}_{2}$ wash for $2 \mathrm{~h}$. The seeds were rinsed $5 \mathrm{x}$ with sterile $\mathrm{ddH}_{2} \mathrm{O}$, plated on Luria-Bertani (LB) (Difco Laboratories, Detroit) agar plates, and incubated at $28^{\circ} \mathrm{C}$ in humidity chambers (plastic boxes with moistened paper towels lining the bottom and the plates separated from the towels by glass petri plates). During the next 3-4 days, clean seeds were carefully separated from any seeds displaying signs of contamination and moved to fresh clean LB plates. After 6 days, clean germinated seeds were selected based on uniform root development and placed in hydroponic units. The hydroponic units consisted of wide mouth 16 oz. mason jars (Ball wide mouth canning jar $16 \mathrm{oz}$ ) with a $125 \mathrm{~mL}$ shaker clamp (Thermo Scientific ${ }^{\mathrm{Tm}}$ MaxQ $^{\mathrm{mm}}$ Shaker Universal Clamps, model 30,153) supporting a five-count plastic canvas mesh stage (circles cut from large plastic sheets and autoclaved separately prior to placing in sterile jars). The units were filled with approximately $225 \mathrm{ml}$ of half strength Murashige and Skoog medium with Gamborg vitamins $(\mathrm{pH}=5.6$, Sigma-Aldrich, St. Louis, MO, U.S.A) amended with $0.05 \%$ sucrose. The tap root of each of five clean seedlings was threaded through the open squares in the plastic mesh insuring the ends of the roots were submerged in MS. The jars were capped with the bottom of sterile plastic $100 \times 15 \mathrm{~mm}$ petri dishes, placed orbital shakers set at $50 \mathrm{rpm}$ (New Brunswick) and incubated at $25-27^{\circ} \mathrm{C}$ with a $16: 8$ light: dark photoperiod. After 5 days, $1 \mathrm{~g}$ T. virens mycelia was added to each jar through a notch cut into the mesh to facilitate adding the mycelia without contacting the roots. The mycelia were filtered from 24-h potato dextrose broth (PDB) cultures (1 $\mathrm{L}$ in Fernbach flasks) that had been inoculated with conidia $\left(1 \times 10^{5} / \mathrm{ml}\right)$ from 10-day old colonies of T. virens. Mycelia were washed $5 \mathrm{X}$ with $\mathrm{dH}_{2} \mathrm{O}$ to remove traces of PDB media. Once the mycelia were added to a jar, a second mason jar (24 oz. wide mouth) was placed on top of the $16 \mathrm{oz}$. jar with parafilm wrapped at the point of contact. This arrangement allowed for unimpeded shoot growth.

\section{Harvesting of plants}

Shoot tissue, root tissue, and fungal biomass were harvested after 6 and $30 \mathrm{~h}$ of co-cultivation. At $6 \mathrm{~h}$ of fungal: maize co-cultivation $T$. virens was visibly growing towards maize roots. Cultivation of maize roots indicated that $T$. virens had not yet colonized the maize roots (Additional file 4: Figure S2). Additionally, $T$. virens and maize were harvested separately for RNA extraction. We defined this timepoint as the "Recognition" phase. At 30 $h$ of co-cultivation, the fungal and maize RNA were extracted from the same tissue sample as fungus was inextricable from maize at this timepoint. We defined this as the "Colonization" phase. After removal from hydroponic media all tissues samples were immediately stored in liquid nitrogen until preservation at $-80^{\circ} \mathrm{C}$.

\section{RNA extraction}

RNA was extracted from ten biological replicates of maize co-cultivated with $T$. virens and four biological replicates of $T$. virens grown alone using a modified method for the Qiagen RNeasy Plant Mini Kit. The tissue samples were first ground in liquid nitrogen, and $100 \mathrm{mg}$ of the tissue was aliquoted for RNA extraction. While the samples were still chilled in liquid nitrogen, 1 mL TRI reagent (Molecular Research Center Inc., Cat. TR118) was added to each sample and vortexed. The samples were then left at room temperature for $5 \mathrm{~min}$ before $200 \mu \mathrm{L}$ chloroform was added and mixed by inversion. The samples incubated at room temperature for $10 \mathrm{~min}$ before being centrifuged at $13,000 \times \mathrm{g}$ at $4{ }^{\circ} \mathrm{C}$ for $15 \mathrm{~min}$. The supernatant was transferred to a new tube with $500 \mu \mathrm{L}$ isopropanol. The samples were gently mixed by inversion and stored at room temperature for $10 \mathrm{~min}$. The samples were then transferred into the Qiagen RNeasy Plant Mini Kit (Qiagen, Hilden, Germany, Cat\# 74903) spin columns (pink). The samples were then 
processed following the remaining steps of the Qiagen RNeasy Plant Mini Kit's instructions.

\section{RNA-sequencing}

Total extracted RNA was provided to the Texas A\&M AgriLifeGenomics and Bioinformatics Service. For samples extracted $30 \mathrm{~h}$ after fungal-maize co-cultivation, the submitted gRNA was composed of both fungal and plant RNA. Preliminary sequencing showed that this combined RNA sample was primarily fungal RNA. Samples extracted at $6 \mathrm{~h}$ were recombined in a 20:80 (fungal: maize) ratio to mimic the $30 \mathrm{~h}$ samples and allow sufficient material for sequencing of maize RNA; analysis of maize RNA will be presented elsewhere. cDNA libraries were created with the NEXTflex ${ }^{\circ}$ Rapid Illumina Directional RNA-Seq Library Prep Kit. Sequencing was done on a NovaSeq 6000 , for $50 \mathrm{bp}$ paired end reads to a depth of 250 million reads.

\section{Data analysis}

Base-calling, quality checking, and removal of adaptor sequences was performed by at the Texas A\&M AgriLife Genomic and Bioinformatics Service as per their standard operating procedure. Raw, paired end, $50 \mathrm{bp}$ reads were then aligned back to the Trichoderma virens Gv29-8 genome (NCBI accession number GCA_000170995.2) via the TopHat2 v2.1.0 pipeline [89] Alignment rates varied, dependent on whether samples were composed of only fungal RNA or a mix of fungal/plant RNA (Additional file 6: Figure S3). Uniquely aligned reads were counted with the HT-Seq 0.6.1 pipeline [90] using the GenBank GCA_000170995.2_TRIVI_v2.0_genomic file for annotation. Multi-dimensional scaling of rlog transformed HT-Seq data showed clear separation of fungal transcriptome clusters between treatments (Additional file 7: Figure S4).

FPKM values were calculated from the HT-seq output by the following equation:

$(\operatorname{read}$ number $/ \mathrm{mRNA} \mathrm{kb}) /\left(\right.$ total number of $\left.\operatorname{reads} / 10^{6}\right)$

Differential expression analysis was conducted using the DeSeq2 1.16.1 pipeline which normalizes libraries based on the geometric mean of the read counts and then calculates the $\log _{2}$ fold change between a defined 'experimental' and 'reference' sample [91]. Experimental samples were $T$. virens grown with maize and reference samples $T$. virens grown alone. DEGs (differentially expressed genes) were considered significant if a $\log _{2}$ fold change was \pm 1.5 with a $\mathrm{p}$ adjusted value of $<0.05$. Significant DEGs were manually assigned general categories of function based on the Kyto Orthology of Genes (KEGG, [92]), GO Term (Gene Ontology, [93]), CAZY (Carbohydrate-Active enZymes Database, [94]), and protein domains as annotated in JGI
(Joint Genome Institute, [95]) version 2.0 T. virens Gv298 catalogue [31]. These functional categories are not meant to represent absolute function, but a general method of data organization.

\section{RNA-sequencing validation}

Gene expression identified by RNA-seq was validated with quantitative reverse-transcriptase polymerase chain reaction (RT-qPCR). Validation genes were selected to represent a range of $\log _{2}$ fold changes, between the fungus grown alone and with maize at both the Recognition and Colonization datasets (Additional file 8: Table S1). RNA was freshly extracted from three biological replicates of plant and fungal tissue from each condition which had been stored at $-80 \mathrm{C}$. These frozen tissue samples were collected in the original hydroponics experiment but were replicates not submitted for RNA-Seq. RNA was extracted as described above (section, RNA Extraction.). $2 \mu \mathrm{g}$ of total RNA in a $20 \mu \mathrm{l}$ reaction was converted to cDNA with a High Capacity cDNA Reverse Transcription Kit (Applied Biosystems, USA) by manufacturer operating procedure on a BLANK thermocycler with the following conditions: $25^{\circ} \mathrm{C}$ for $10 \mathrm{~min}, 37^{\circ} \mathrm{C}$ for 120 min, $85^{\circ} \mathrm{C}$ for five minutes, followed by a hold at $4^{\circ}$ $\mathrm{C}$ until use in RT-qPCR reaction. $1 \mu \mathrm{l}$ of cDNA reaction was used as the input for $\mathrm{qPCR}$ reaction. $\mathrm{qPCR}$ reactions were made with a PowerUp SYBR Green Kit (Applied Biosystems, USA) by manufacturer operating procedure in a $10 \mu \mathrm{l}$ volume. qPCR was done a StepOne Plus Real-Time PCR system with the following cycling conditions: $50^{\circ} \mathrm{C}$ for $2 \mathrm{~min}, 95^{\circ} \mathrm{C}$ for 2 min, followed by 40 cycles of $95^{\circ} \mathrm{C}(15 \mathrm{~s}), 53^{\circ} \mathrm{C}(15 \mathrm{~s})$, $72{ }^{\circ} \mathrm{C}(15 \mathrm{~s})$. Melt curve conditions were $95^{\circ} \mathrm{C}$ for 15 s, $60^{\circ} \mathrm{C}$ for $1 \mathrm{~min}, 95^{\circ} \mathrm{C}$ for $15 \mathrm{~s}$. All samples had only one melt temperature peak. $\log _{2}$ fold change between experimental samples ( $T$. virens with maize) and control samples ( $T$. virens grown alone) was calculated by the $2^{\wedge^{-\Delta}} \Delta \mathrm{CT}$ method using actin as a reference gene (Additional file 8: Table S1). CT values represent the average of three technical replicates (Additional file 1: Figure S1).

\section{Identification of secondary metabolite clusters}

Sequences of the genes in the vicinity of signature genes (e.g., NRPS, PKS, terpene cyclase) in respective scaffolds were analyzed for presence of domains putatively involved in secondary metabolism (like cytochrome P450, oxidoreductase, glutathione S-transferase) by NCBI CDD database search. The boundaries of the putative gene clusters were defined by the presence of genes not known to be involved in secondary metabolism. 


\section{Additional files}

Additional file 1: Figure S2. T. virens has recognized but not colonized B73 Maize after $6 \mathrm{~h}$ of hydroponic co-cultivation. Plant grow hydroponically, as described in methods, were harvested at 6 then $30 \mathrm{~h}$ post inoculation with $T$. virens ( $N=3$ per harvest). Roots were dissected into $1 \mathrm{~cm}$ pieces and plated on GVSM. The number of root pieces with fungal growth after three days of incubation at $27^{\circ} \mathrm{C}$ was counted and divided by the total root pieces plates to get a percentage colonized for each plant. (PPTX $35 \mathrm{~kb}$ )

Additional file 2: Data file S1. Excel file with $\log _{2}$ fold changes and $p$ adjust values for all genes in the T. virens Gv29-8 genome at Recognition and Colonization and calculated FPKM values. (XLSX $5288 \mathrm{~kb}$ )

Additional file 3: Data file S2. Excel file listing the $\log _{2}$ fold changes and $p$-adjust values for all significant DEGs at Recognition and Colonization, with assigned category and function notes. (XLSX 95 kb)

Additional file 4: Figure S1. RT-aPCR validation of RNA-Seq based differential expression analysis. 9 DEGs representing a range of log2fold changes and expression in the Recognition vs Colonization datasets were chosen for validation with RT-qPCR (total of 18 data-points). Points are colored by DEG ID \# to highlight RT-qPCR still captures the direction of the log2fold change when DEGs were oppositely regulated between Recognition and Colonization. The direction of the $\log _{2}$ fold change was in agreement between the two methodologies, though the magnitude of said change was different. This is explicable by the different kits used for cDNA conversion and that the RT-qPCR samples were extracted from tissue held at -80C for 12 months whereas samples used in the RNA-Seq analysis were extracted within one month. Pearson correlation was 0.75 (PPTX $38 \mathrm{~kb}$ )

Additional file 5: Data file S3. Excel file containing database of all genes identified as belonging to a secondary metabolite gene cluster. (XLSX $31 \mathrm{~kb}$ )

Additional file 6: Figure S3. Percentage of reads aligning to the $T$. virens genome and the sequenced coverage of the $T$. virens represented by aligned reads. (PPTX $43 \mathrm{~kb}$ )

Additional file 7: Figure S4. Multi-dimensional plot of each RNA-seq library: T. virens grown without maize at $6 \mathrm{~h}$ (no B73_6hr), T. virens growth without maize at $30 \mathrm{~h}$ (no B73 30hr), T. virens cultivated with maize for 6 h (with B73_6hr) and for $30 \mathrm{~h}$ (with B73_30hr). Clustering shows close intra-condition clustering. (PPTX $117 \mathrm{~kb}$ )

Additional file 8: Table S1. List of genes and primer sequences used for RT-qPCR validation of RNA-Seq differential expression analysis. (DOCX $14 \mathrm{~kb})$

\section{Abbreviations}

CAZ: Carbohydrate activated enzyme; CWDE: Cell wall degrading enzyme; DE: Differential expression; DEG: Differentially expressed gene; IAA: Indole-3acetic acid; JA: Jasmonic acid; RT-qPCR: Quantitative-real-time polymerase chain reaction; SA: Salicylic acid

\section{Acknowledgements}

PKM visit to CMK lab was made possible by a Fulbright Visiting Scholarship. Authors would also like to acknowledge the Texas A\&M AgriLife Genomics and Bioinformatics Service for sequencing services and the Texas A\&M High Computing Research Center for providing supercomputing capability for RNA-Seq analysis.

\section{Funding}

A USDA-NIFA grant, Award No 2016-67013-24730, provided funds for the implementation of this study, including costs for experimental set-up, sequencing, and post-doc salary for data analysis and manuscript preparation.

\section{Availability of data and materials}

The datasets used and/or analyzed during the current study are available from the corresponding author on reasonable request.

\section{Authors' contributions}

EM was responsible for data analysis, interpretation, and manuscript preparation. KW was responsible for experimental set-up and RNA extraction from samples for RNA-seq. PKM contributed extensive knowledge on Trichoderma secondary metabolite biosynthesis, used in describing secondary metabolite results. PKM also identified all secondary metabolite clusters, presented in Additional file 5: Data file S3. MK and CMK are co-authors on the grant supporting this work and gave substantial intellectual contribution to the experimental design, data analysis, and editing of the final manuscript. All authors read and approved the final manuscript.

\section{Ethics approval and consent to participate}

NA.

\section{Consent for publication}

NA.

\section{Competing interests}

The authors declare that they have no competing interests.

\section{Publisher's Note}

Springer Nature remains neutral with regard to jurisdictional claims in published maps and institutional affiliations.

Received: 10 August 2018 Accepted: 27 March 2019

Published online: 11 April 2019

\section{References}

1. Mukherjee PK, Horwitz BA, Herrera-Estrella A, Schmoll M, Kenerley CM. Trichoderma research in the genome era. Annu Rev Phytopathol. 2013;51: 105-29.

2. Contreras-Cornejo HA, Macías-Rodríguez L, Cortés-Penagos C, López-Bucio J. Trichoderma virens, a plant beneficial fungus, enhances biomass production and promotes lateral root growth through an auxin-dependent mechanism in Arabidopsis. Plant Physiol. 2009;149(3):1579-92.

3. Schmoll M, Dattenböck C, Carreras-Villaseñor N, Mendoza-Mendoza A, Tisch D, Alemán Ml, Baker SE, Brown C, Cervantes-Badillo MG, Cetz-Chel J, Cristobal-Mondragon GR. The genomes of three uneven siblings: footprints of the lifestyles of three Trichoderma species. Microbiol Mol Biol Rev. 2016: 80(1):205-327.

4. Zeilinger S, Omann M. Trichoderma biocontrol: signal transduction pathways involved in host sensing and mycoparasitism. Gene regulation and systems biology. 2007;1:227-34 GRSB-S397.

5. Chacón MR, Rodríguez Galán $O$, Benítez Fernández $C T$, Sousa S, Rey M, Llobell González A, Delgado Jarana J. Microscopic and transcriptome analyses of early colonization of tomato roots by Trichoderma harzianum. Int Microbiol. 2007;10(1):19-27

6. Mukherjee M, Mukherjee PK, Horwitz BA, Zachow C, Berg G, Zeilinger S. Trichoderma-plant-pathogen interactions: advances in genetics of biological control. Indian J Microbiol. 2012;52(4):522-9.

7. Nogueira-Lopez G, Greenwood DR, Middleditch M, Winefield C, Eaton C, Steyaert JM, Mendoza-Mendoza A. The apoplastic secretome of Trichoderma virens during interaction with maize roots shows an inhibition of plant defense and scavenging oxidative stress secreted proteins. Front Plant Sci. 2018;9:409.

8. Viterbo AD, Chet I. TasHyd1, a new hydrophobin gene from the biocontrol agent Trichoderma asperellum, is involved in plant root colonization. Mol Plant Pathol. 2006;7(4):249-58.

9. Alonso-Ramírez A, Poveda J, Martín I, Hermosa R, Monte E, Nicolás C. Salicylic acid prevents Trichoderma harzianum from entering the vascular system of roots. Mol Plant Pathol. 2014;15:823-31.

10. Navarro-Meléndez AL, Heil M. Symptomless endophytic fungi suppress endogenous levels of salicylic acid and interact with the jasmonatedependent indirect defense traits of their host, Lima bean (Phaseolus lunatus). J Chem Ecol. 2014;40(7):816-25.

11. Martínez-Medina A, Fernandez I, Lok GB, Pozo MJ, Pieterse CM, Van Wees S. Shifting from priming of salicylic acid-to jasmonic acid-regulated defenses by Trichoderma protects tomato against the root knot nematode Meloidogyne incognita. New Phytol. 2017;213(3):1363-77.

12. Jogaiah S, Abdelrahman M, Tran LS, Ito SI. Different mechanisms of Trichoderma virens-mediated resistance in tomato against Fusarium wilt 
involve the jasmonic and salicylic acid pathways. Mol Plant Pathol. 2018; 19(4):870-82.

13. Contreras-Cornejo HA, Macías-Rodríguez L, del-Val E, Larsen J. Ecological functions of Trichoderma spp. and their secondary metabolites in the rhizosphere: interactions with plants. FEMS Microbiol Ecol. 2016;92:fiw036.

14. Constantino NN, Mastouri F, Damarwinasis R, Borrego EJ, Moran-Diez ME, Kenerley CM, et al. Root-expressed maize lipoxygenase 3 negatively regulates induced systemic resistance to Colletotrichum graminicola in shoots. Front Plant Sci. 2013;4:510

15. Djonović S, Pozo MJ, Dangott LJ, Howell CR, Kenerley CM. Sm1, a proteinaceous elicitor secreted by the biocontrol fungus Trichoderma virens induces plant defense responses and systemic resistance. Mol Plant-Microbe Interact. 2006;19:838-53.

16. Djonović S, Vargas WA, Kolomiets MV, Horndeski M, Wiest A, Kenerley CM. A proteinaceous elicitor $\mathrm{Sm} 1$ from the beneficial fungus Trichoderma virens is required for induced systemic resistance in maize. Plant Physiol. 2007;145: 875-89.

17. Viterbo AD, Wiest AR, Brotman Y, Chet IL, Kenerley C. The 18mer peptaibols from Trichoderma virens elicit plant defense responses. Mol Plant Pathol. 2007:8(6):737-46.

18. Mukherjee PK, Buensanteai N, Moran-Diez ME, Druzhinina IS, Kenerley CM. Functional analysis of non-ribosomal peptide synthetases (NRPSs) in Trichoderma virens reveals a polyketide synthase (PKS)/NRPS hybrid enzyme involved in the induced systemic resistance response in maize. Microbiology. 2012;158(1):155-65.

19. Schuster A, Schmoll M. Biology and biotechnology of Trichoderma. Appl Microbiol Biotechnol. 2010;87(3):787-99.

20. Morán-Diez ME, Trushina N, Lamdan NL, Rosenfelder L, Mukherjee PK, Kenerley CM, Horwitz BA. Host-specific transcriptomic pattern of Trichoderma virens during interaction with maize or tomato roots. BMC Genomics. 2015;16(1):8.

21. Lamdan NL, Shalaby S, Ziv T, Kenerley CM, Horwitz BA. Secretome of the biocontrol fungus Trichoderma virens co-cultured with maize roots: role in induced systemic resistance. Mol Cell Proteomics. 2015;14(4):1054-63 mcpM114.

22. Aro N, Pakula T, Penttilä M. Transcriptional regulation of plant cell wall degradation by filamentous fungi. FEMS Microbiol Rev. 2005;29:719-39.

23. Gruber $S$, Seidl-Seiboth V. Self versus non-self: fungal cell wall degradation in Trichoderma. Microbiology. 2012;158:26-34.

24. Bailey BA, Bae H, Strem MD, Roberts DP, Thomas SE, Crozier J, et al. Fungal and plant gene expression during the colonization of cacao seedlings by endophytic isolates of four Trichoderma species. Planta. 2006;224:1449-64.

25. Norman-Setterblad C, Vidal S, Palva ET. Interacting signal pathways control defense gene expression in Arabidopsis in response to cell wall-degrading enzymes from Erwinia carotovora. Mol Plant-Microbe Interact. 2000;13(4): 430-8.

26. Ma Z, Song T, Zhu L, Ye W, Wang Y, Shao Y, Dong S, Zhang Z, Dou D, Zheng X, Tyler BM. A Phytophthora sojae glycoside hydrolase 12 protein is a major virulence factor during soybean infection and is recognized as a PAMP. Plant cell. 2015;27(7):2057-72.

27. Falcón-Rodríguez AB, Wégria G, Cabrera JC. Exploiting plant innate immunity to protect crops against biotic stress: chitosaccharides as natural and suitable candidates for this purpose. New perspectives in plant protection. London: InTech; 2012. p. 140-151.

28. Zhang $Y$, Zhang $Y$, Qiu D, Zeng $H$, Guo L, Yang X. BcGs 1, a glycoprotein from Botrytis cinerea, elicits defense response and improves disease resistance in host plants. Biochem Biophys Res Commun. 2015;457(4):627-34.

29. Benoit I, Coutinho PM, Schols HA, Gerlach JP, Henrissat B, de Vries RP. Degradation of different pectins by fungi: correlations and contrasts between the pectinolytic enzyme sets identified in genomes and the growth on pectins of different origin. BMC Genomics. 2012;13:321.

30. Hermosa R, Rubio MB, Cardoza RE, Nicolás C, Monte E, Gutiérrez S, et al. The contribution of Trichoderma to balancing the costs of plant growth and defense. Int Microbiol. 2013;16:69-80.

31. Kubicek CP, Herrera-Estrella A, Seidl-Seiboth V, Martinez DA, Druzhinina IS, Thon M, Zeilinger S, Casas-Flores S, Horwitz BA, Mukherjee PK, Mukherjee M. Comparative genome sequence analysis underscores mycoparasitism as the ancestral life style of Trichoderma. Genome Biol. 2011;12(4):1.

32. Woo SL, Scala F, Ruocco M, Lorito M. The molecular biology of the interactions between Trichoderma spp., phytopathogenic fungi, and plants. Phytopathology. 2006;96(2):181-5.
33. Margolles-Clark E, Ihnen M, Penttilä M. Expression patterns of ten hemicellulase genes of the filamentous fungus Trichoderma reesei on various carbon sources. J Biotechnol. 1997;57(1-3):167-79.

34. Alkooranee JT, Aledan TR, Ali AK, Lu G, Zhang X, Wu J, et al. Detecting the hormonal pathways in oilseed rape behind induced systemic resistance by Trichoderma harzianum TH12 to Sclerotinia sclerotiorum. PLOS One. 2017;12: e0168850.

35. Fischer GJ, Keller NP. Production of cross-kingdom oxylipins by pathogenic fungi: an update on their role in development and pathogenicity. J Microbiol. 2016;54:254-64.

36. Newman JW, Morisseau C, Hammock BD. Epoxide hydrolases: their roles and interactions with lipid metabolism. Prog Lipid Res. 2005;44(1):1-51.

37. Mueller MJ. Enzymes involved in jasmonic acid biosynthesis. Physiol Plant. 1997;100(3):653-63.

38. Affeldt KJ, Brodhagen M, Keller NP. Aspergillus oxylipin signaling and quorum sensing pathways depend on $\mathrm{G}$ protein-coupled receptors. Toxins. 2012:4:695-717.

39. Schneider K, Hövel K, Witzel K, Hamberger B, Schomburg D, Kombrink E, Stuible HP. The substrate specificity-determining amino acid code of 4coumarate: CoA ligase. Proc Natl Acad Sci. 2003;100(14):8601-6.

40. Pourcel L, Routaboul JM, Cheynier V, Lepiniec L, Debeaujon I. Flavonoid oxidation in plants: from biochemical properties to physiological functions. Trends Plant Sci. 2007;12(1):29-36.

41. Shanmugam V, Ronen M, Shalaby S, Larkov O, Rachamim Y, Hadar R, Rose MS, Carmeli S, Horwitz BA, Lev S. The fungal pathogen Cochliobolus heterostrophus responds to maize phenolics: novel small molecule signals in a plant-fungal interaction. Cell Microbiol. 2010;12(10):1421-34.

42. Rudrappa T, Quinn WJ, Stanley-Wall NR, Bais HP. A degradation product of the salicylic acid pathway triggers oxidative stress resulting in downregulation of Bacillus subtilis biofilm formation on Arabidopsis thaliana roots. Planta. 2007;226(2):283-97.

43. Rabe F, Ajami-Rashidi Z, Doehlemann G, Kahmann R, Djamei A. Degradation of the plant defense hormone salicylic acid by the biotrophic fungus $U$ stilago maydis. Mol Microbiol. 2013;89(1):179-88.

44. El-Katatny MH. Enzyme production and nitrogen fixation by free, immobilized and co-immobilized inoculants of Trichoderma harzianum and Azospirillum brasilense and their possible role in growth promotion of tomato. Food Technol Biotechnol. 2010;48(2):161-74.

45. Gupta KJ, Mur LAJ, Brotman Y. Trichoderma asperelloides suppresses nitric oxide generation elicited by Fusarium oxysporum in Arabidopsis roots. Mol Plant-Microbe Interact. 2014;27:307-14.

46. Harman GE, Howell CR, Viterbo A, Chet I, Lorito M. Trichoderma species_opportunistic, avirulent plant symbionts. Nat Rev Microbiol. 2004;2:43.

47. Baxter A, Mittler R, Suzuki N. ROS as key players in plant stress signalling. J Exp Bot. 2014;65:1229-40.

48. Liu X, Williams CE, Nemacheck JA, Wang H, Subramanyam S, Zheng C, Chen MS. Reactive oxygen species are involved in plant defense against a gall midge. Plant Physiol. 2010;152(2):985-99.

49. Delledonne M, Murgia I, Ederle D, Sbicego PF, Biondani A, Polverari A, et al. Reactive oxygen intermediates modulate nitric oxide signaling in the plant hypersensitive disease-resistance response. Plant Physiol Biochem. 2002;40: 605-10.

50. Low PS, Merida JR. The oxidative burst in plant defense: function and signal transduction. Physiol Plant. 1996;96(3):533-42.

51. Santos R, Hérouart D, Sigaud S, Touati D, Puppo A. Oxidative burst in alfalfaSinorhizobium meliloti symbiotic interaction. Mol Plant-Microbe Interact. 2001;14(1):86-9.

52. Hossain MA, Piyatida P, da Silva JAT, Fujita M. Molecular mechanism of heavy metal toxicity and tolerance in plants: central role of glutathione in detoxification of reactive oxygen species and methylglyoxal and in heavy metal chelation. J Bot. 2012;2012:1-37. https://doi.org/10.1155/2012/872875.

53. Dixit P, Mukherjee PK, Ramachandran V, Eapen S. Glutathione transferase from Trichoderma virens enhances cadmium tolerance without enhancing its accumulation in transgenic Nicotiana tabacum. PLoS One. 2011;6:e16360.

54. Babu AG, Shim J, Bang K-S, Shea PJ, Oh B-T. Trichoderma virens PDR-28: a heavy metal-tolerant and plant growth-promoting fungus for remediation and bioenergy crop production on mine tailing soil. J Environ Manag. 2014; 132:129-34.

55. Vinale F, Sivasithamparam K, Ghisalberti EL, Marra R, Barbetti MJ, Li H, Woo SL, Lorito M. A novel role for Trichoderma secondary metabolites in the interactions with plants. Physiol Mol Plant Pathol. 2008;72(1-3):80-6. 
56. Pozo MJ, Baek JM, Garcia JM, Kenerley CM. Functional analysis of tvsp 1, a serine protease-encoding gene in the biocontrol agent Trichoderma virens. Fungal Genet Biol. 2004;41(3):336-48.

57. Arjona-Girona I, Vinale F, Ruano-Rosa D, Lorito M, López-Herrera CJ. Effect of metabolites from different Trichoderma strains on the growth of Rosellinia necatrix, the causal agent of avocado white root rot. Eur J Plant Pathol. 2014;140:385-97

58. Wilhite SE, Straney DC. Timing of gliotoxin biosynthesis in the fungal biological control agent Gliocladium virens (Trichoderma virens). Appl Microbiol Biotechnol. 1996;45(4):513-8.

59. Atanasova L, Knox BP, Kubicek CP, Druzhinina IS, Baker SE. The polyketide synthase gene pks4 of Trichoderma reesei provides pigmentation and stress resistance. Eukaryotic cell. 2013;12(11):1499-508 EC-00103.

60. Bansal R, Sherkhane PD, Oulkar D, Khan Z, Banerjee K, Mukherjee PK. The viridin biosynthesis gene cluster of Trichoderma virens and its conservancy in the bat white-nose fungus Pseudogymnoascus destructans. Chemistry Select. 2018;3(4):1289-93.

61. Mukherjee PK, Hadar R, Pardovitz-Kedmi E, Trushina N, Horwitz BA. MRSP1, encoding a novel Trichoderma secreted protein, is negatively regulated by MAPK. Biochem Biophys Res Commun. 2006;350(3):716-22.

62. Mukherjee PK, Latha J, Hadar R, Horwitz BA. TmkA, a mitogen-activated protein kinase of Trichoderma virens, is involved in biocontrol properties and repression of conidiation in the dark. Eukaryot Cell. 2003;2(3):446-55.

63. Gaderer R, Lamdan NL, Frischmann A, Sulyok M, Krska R, Horwitz BA, et al. Sm2, a paralog of the Trichoderma cerato-platanin elicitor Sm1, is also highly important for plant protection conferred by the fungal-root interaction of Trichoderma with maize. BMC Microbiol. 2015;15:2.

64. Mendoza-Mendoza A, Zaid R, Lawry R, Hermosa R, Monte E, Horwitz BA, Mukherjee PK. Molecular dialogues between Trichoderma and roots: role of the fungal secretome. Fungal Biol Rev. 2018;32(2):62-85.

65. Snelders NC, Kettles GJ, Rudd JJ, Thomma BP. Plant pathogen effector proteins as manipulators of host microbiomes? Mol Plant Pathol. 2018;19(2):257-9.

66. Brotman Y, Landau U, Cuadros-Inostroza Á, Takayuki T, Fernie AR, Chet I, et al. Trichoderma-plant root colonization: escaping early plant defense responses and activation of the antioxidant machinery for saline stress tolerance. PLoS Pathology. 2013;9:e1003221.

67. Bonazza K, Gaderer R, Neudl S, Przylucka A, Allmaier G, Druzhinina IS, et al. The fungal cerato-platanin protein EPL1 forms highly ordered layers at hydrophobic/hydrophilic interfaces. Soft Matter. 2015;11:1723-32. https:// doi.org/10.1039/C4SM02389G.

68. Hermosa R, Viterbo A, Chet I, Monte E. Plant-beneficial effects of Trichoderma and of its genes. Microbiology. 2012;158(1):17-25.

69. Przylucka A, Akcapinar GB, Chenthamara K, Cai F, Grujic M, Karpenko J, Livoi M, Shen Q, Kubicek CP, Druzhinina IS. HFB7-a novel orphan hydrophobin of the Harzianum and Virens clades of Trichoderma, is involved in response to biotic and abiotic stresses. Fungal Genet Biol. 2017;102:63-76.

70. Askolin S, Penttilä M, Wösten HA, Nakari-Setälä T. The Trichoderma reesei hydrophobin genes hfb1 and hfb2 have diverse functions in fungal development. FEMS Microbiol Lett. 2005;253(2):281-8.

71. Fesel PH, Zuccaro A. $\beta$-glucan: Crucial component of the fungal cell wall and elusive MAMP in plants. Fungal Genet Biol. 2016;90:53-60.

72. De Jonge R, Van Esse HP, Kombrink A, Shinya T, Desaki Y, Bours R, et al. Conserved fungal LysM effector Ecp6 prevents chitin-triggered immunity in plants. Science. 2010;329:953-5.

73. Sánchez-Vallet A, Saleem-Batcha R, Kombrink A, Hansen G, Valkenburg DJ, Thomma BP, Mesters JR. Fungal effector Ecp6 outcompetes host immune receptor for chitin binding through intrachain LysM dimerization. elife. 2013;2:e00790.

74. Heras B, Shouldice SR, Totsika M, Scanlon MJ, Schembri MA, Martin JL. DSB proteins and bacterial pathogenicity. Nat Rev Microbiol. 2009;7:215.

75. Jin H, Martin C. Multifunctionality and diversity within the plant MYB-gene family. Plant Mol Biol. 1999;41(5):577-85.

76. Rocak S, Linder P. DEAD-box proteins: the driving forces behind RNA metabolism. Nat Rev Mol Cell Biol. 2004;5(3):232.

77. Viterbo A, Harel M, Horwitz BA, Chet I, Mukherjee PK. Trichoderma mitogenactivated protein kinase signaling is involved in induction of plant systemic resistance. Appl Environ Microbiol. 2005;71(10):6241-6.

78. Mukherjee PK, Latha J, Hadar R, Horwitz BA. Role of two G-protein alpha subunits, TgaA and TgaB, in the antagonism of plant pathogens by Trichoderma virens. Appl Environ Microbiol. 2004;70(1):542-9.

79. Kumar A, Scher K, Mukherjee M, Pardovitz-Kedmi E, Sible GV, Singh US, Kale SP, Mukherjee PK, Horwitz BA. Overlapping and distinct functions of two
Trichoderma virens MAP kinases in cell-wall integrity, antagonistic properties and repression of conidiation. Biochem Biophys Res Commun. 2010;398(4): 765-70.

80. Navazio L, Baldan B, Moscatiello R, Zuppini A, Woo SL, Mariani P, Lorito M. Calcium-mediated perception and defense responses activated in plant cells by metabolite mixtures secreted by the biocontrol fungus Trichoderma atroviride. BMC Plant Biol. 2007;7(1):41.

81. Peiter E. The plant vacuole: emitter and receiver of calcium signals. Cell Calcium. 2011;50(2):120-8.

82. Vargas WA, Mandawe JC, Kenerley CM. Plant-derived sucrose is a key element in the symbiotic association between Trichoderma virens and maize plants. Plant Physiol. 2009;151(2):792-808.

83. Vargas WA, Crutcher FK, Kenerley CM. Functional characterization of a plantlike sucrose transporter from the beneficial fungus Trichoderma virens. Regulation of the symbiotic association with plants by sucrose metabolism inside the fungal cells. New Phytol. 2011;189(3):777-89.

84. Harman GE. Multifunctional fungal plant symbionts: new tools to enhance plant growth and productivity. New Phytol. 2011;189:647-9.

85. Berkey R, Bendigeri D, Xiao S. Sphingolipids and plant defense/disease: the "death" connection and beyond. Front Plant Sci. 2012;3:68.

86. Dickson RC, Lester RL. Metabolism and selected functions of sphingolipids in the yeast Saccharomyces cerevisiae. Biochim Biophys Acta (BBA)-molecular and cell biology of lipids. 1999;1438(3):305-21.

87. Yew SM, Chan CL, Kuan CS, Toh YF, Ngeow YF, Na SL, Lee KW, Hoh CC, Yee WY, Ng KP. The genome of newly classified Ochroconis mirabilis: insights into fungal adaptation to different living conditions. BMC Genomics. 2016; 17(1):91.

88. Udatha DG, Topakas E, Salazar M, Olsson L, Andersen MR, Panagiotou G. Deciphering the signaling mechanisms of the plant cell wall degradation machinery in Aspergillus oryzae. BMC Syst Biol. 2015;9(1):77.

89. Kim D, Pertea G, Trapnell C, Pimentel H, Kelley R, Salzberg SL. TopHat2: accurate alignment of transcriptomes in the presence of insertions, deletions and gene fusions. Genome Biol. 2013;14(4):R36.

90. Anders S, Pyl PT, Huber W. HTSeq--a Python framework to work with highthroughput sequencing data. Bioinformatics. 2015;31:166-9.

91. Love Ml, Huber W, Anders S. Moderated estimation of fold change and dispersion for RNA-seq data with DESeq2. Genome Biol. 2014;15(12):550.

92. Kanehisa M, Sato Y, Kawashima M, Furumichi M, Tanabe M. KEGG as a reference resource for gene and protein annotation. Nucleic Acids Res. 2015;44(D1):D457-62.

93. Ashburner M, Ball C, Blake J, Botstein D, Butler H, Cherry J, et al. Gene ontology: tool for the unification of biology. Nat Genet. 2000;25:25.

94. Lombard V, Golaconda Ramulu H, Drula E, Coutinho PM, Henrissat B. The carbohydrate-active enzymes database (CAZy) in 2013. Nucleic Acids Res. 2013;42(D1):D490-5.

95. Nordberg H, Cantor M, Dsheyko S, Hua S, Poliakov A, Shabalov I, Smirnova T, Grigoriev IV, Dubchak I. The genome portal of the Department of Energy Joint Genome Institute: 2014 updates. Nucleic Acids Res. 2013;42(D1):D2631.
Ready to submit your research? Choose BMC and benefit from:
- fast, convenient online submission
- thorough peer review by experienced researchers in your field
- rapid publication on acceptance
- support for research data, including large and complex data types
- gold Open Access which fosters wider collaboration and increased citations
- maximum visibility for your research: over $100 \mathrm{M}$ website views per year
At BMC, research is always in progress.
Learn more biomedcentral.com/submissions 